\title{
Interaction of Polyamines, Abscisic Acid, Nitric Oxide, and Hydrogen Peroxide under Chilling Stress in Tomato (Lycopersicon esculentum Mill.) Seedlings
}

OPEN ACCESS

Edited by:

Vasileios Fotopoulos, Cyprus University of Technology, Cyprus

Reviewed by:

Girish Mishra,

University of Delhi, India

Athanassios Molassiotis,

Aristotle University of Thessaloniki,

Greece

${ }^{*}$ Correspondence: Hongyan Q

hyqiaaa@126.com;

syauhongyan@hotmail.com

tThese authors have contributed equally to this work.

Specialty section: This article was submitted to Plant Physiology,

a section of the journal

Frontiers in Plant Science

Received: 08 September 2016 Accepted: 02 February 2017

Published: 14 February 2017

Citation:

Diao Q, Song Y, Shi D and Qi H (2017) Interaction of Polyamines,

Abscisic Acid, Nitric Oxide, and Hydrogen Peroxide under Chilling

Stress in Tomato (Lycopersicon esculentum Mill.) Seedlings.

Front. Plant Sci. 8:203.

doi: 10.3389/fpls.2017.00203

\section{Qiannan Diao ${ }^{1,2 t}$, Yongjun Song ${ }^{1,2 t}$, Dongmei Shi ${ }^{1,2}$ and Hongyan $\mathrm{Qi}^{1,2 *}$}

${ }^{1}$ College of Horticulture, Shenyang Agricultural University, Shenyang, China, ${ }^{2}$ Key Laboratory of Protected Horticulture of Ministry of Education and Liaoning Province, Collaborative Innovation Center of Protected Vegetable Surround Bohai Gulf Region, Shenyang, China

Polyamines (PAs) play a vital role in the responses of higher plants to abiotic stresses. However, only a limited number of studies have examined the interplay between PAs and signal molecules. The aim of this study was to elucidate the cross-talk among PAs, abscisic acid (ABA), nitric oxide (NO), and hydrogen peroxide $\left(\mathrm{H}_{2} \mathrm{O}_{2}\right)$ under chilling stress conditions using tomato seedlings [(Lycopersicon esculentum Mill.) CV. Moneymaker]. The study showed that during chilling stress $\left(4^{\circ} \mathrm{C} ; 0,12\right.$, and $\left.24 \mathrm{~h}\right)$, the application of spermidine (Spd) and spermine (Spm) elevated $\mathrm{NO}$ and $\mathrm{H}_{2} \mathrm{O}_{2}$ levels, enhanced nitrite reductase (NR), nitric oxide synthase (NOS)-like, and polyamine oxidase activities, and upregulated LeNR relative expression, but did not influence LeNOS1 expression. In contrast, putrescine (Put) treatment had no obvious impact. During the recovery period $\left(25 / 15^{\circ} \mathrm{C}, 10 \mathrm{~h}\right)$, the above-mentioned parameters induced by the application of PAs were restored to their control levels. Seedlings pretreated with sodium nitroprusside (SNP, an NO donor) showed elevated Put and Spd levels throughout the treatment period, consistent with increased expression in leaves of genes encoding arginine decarboxylase (LeADC, LeADC1), ornithine decarboxylase (LeODC), and Spd synthase (LeSPDS) expressions in tomato leaves throughout the treatment period. Under chilling stress, the Put content increased first, followed by a rise in the Spd content. Exogenously applied SNP did not increase the expression of genes encoding S-adenosylmethionine decarboxylase (LeSAMDC) and Spm synthase (LeSPMS), consistent with the observation that Spm levels remained constant under chilling stress and during the recovery period. In contrast, exogenous Put significantly increased the ABA content and the 9-cis-epoxycarotenoid dioxygenase (LeNCED1) transcript level. Treatment with ABA could alleviate the electrolyte leakage (EL) induced by D-Arg (an inhibitor of Put). Taken together, it is concluded that, under chilling stress, Spd and Spm enhanced the production of $\mathrm{NO}$ in tomato seedlings through an $\mathrm{H}_{2} \mathrm{O}_{2}$-dependent mechanism, via the NR and NOS-like pathways. ABA is involved in Put-induced tolerance to chilling stress, and NO could increase the content of Put and Spd under chilling stress.

Keywords: polyamines, hydrogen peroxide, nitric oxide, abscisic acid, tomato, chilling stress 


\section{INTRODUCTION}

Chilling stress is a critical factor that can limit crop productivity, since it can affect a range of physiological processes in plants and can cause both metabolic disruption and structural damages (Atıci and Nalbantoğlu, 2003). Therefore, plants have developed a number of strategies to cope with chilling stress, some of which involve the accumulation of ABA (Anderson et al., 1994) and polyamines (PAs) (Shen et al., 2000; Groppa and Benavides, 2008).

Polyamines, principally Put, Spd, and Spm, are low-molecularweight aliphatic amine compounds that are ubiquitous in all plant cells and that participate in a range of cellular processes, including cell division and elongation, morphogenesis, flowering, senescence, and seed germination (Bais and Ravishankar, 2002; Kusano et al., 2007; Gupta et al., 2013). In plants, Put can be synthesized via the decarboxylation of arginine by ADC (EC 4.1.1.19) or of ornithine by ODC (EC 4.1.1.17). Spd and Spm are formed by the addition of an aminopropyl moiety in reactions catalyzed, respectively, by SPDS (EC 2.5.1.16) and SPMS (EC 2.5.1.12). The aminopropyl groups are contributed by decarboxylated $S$-adenosylmethionine (dcSAM), which is derived from $S$-adenosylmethionine (SAM) by the action of SAMDC (EC 4.1.1.50). As has been well documented, DAO (EC 1.4.3.6) and PAO (EC 1.5.3.3) are responsible for the oxidation of PAs in plant cells, which occurs with the concomitant production of $\mathrm{H}_{2} \mathrm{O}_{2}$ (MartinTanguy, 2001). It has been suggested PAs are essential for improving stress tolerance in various plants (Durmus and Kadioglu, 2005; Duan et al., 2008; Arasimowicz-Jelonek et al., 2009; Hu et al., 2012; Li et al., 2014; Minocha et al., 2014). PAs can function directly as protective compounds, thereby enhancing plant tolerance to abiotic stresses; because of their polycationic nature at physiological $\mathrm{pH}$, PAs can interact with negatively charged macromolecules in the cell membrane and can thereby stabilize cell membrane structure under stress conditions (Groppa and Benavides, 2008; Alcázar et al., 2010). In addition to this directly protective role, PAs also interact with other protective molecules, such as ABA, $\mathrm{SA}, \mathrm{GABA}$, and BR, through which they can also modulate stress tolerance (Iqbal et al., 2006; Alcázar et al., 2010; Wang and Zhang, 2012; Espasandin et al., 2014; Hatmi et al., 2015; Serna et al., 2015). Furthermore, PAs may be involved in secondary messenger signaling cross-talk (Alcázar et al., 2010). Recent reports have indicated that PAs are associated with the production of $\mathrm{H}_{2} \mathrm{O}_{2}$ and $\mathrm{NO}$ (Tun et al., 2006; Angelini et al.,

\footnotetext{
Abbreviations: ABA, abscisic acid; ADC, arginine decarboxylase; BR, brassinosteroid; DAO, diamine oxidase; D-Arg, D-arginine; DMTU, dimethylthiourea; DPI, diphenyleneodonium; EL, electrolyte leakage; GABA, gamma-aminobutyric acid; $\mathrm{H}_{2} \mathrm{O}_{2}$, hydrogen peroxide; L-NAME, $\mathrm{N}^{\mathrm{G}}$-nitro-L-Arg methyl ester; NCED, 9-cis-Epoxycarotenoid dioxygenase; NO, nitric oxide; NOS, nitric oxide synthase; NR, nitrite reductase; ODC, ornithine decarboxylase; PAs, polyamines; PAO, polyamine oxidase; PMSF, phenylmethylsulfonyl fluoride; PSII, photosystem II; PTIO, 2-phenyl-4,4,5,5-tetramethylimidazoline-1-oxyl-3-oxide; Put, putrescine; PVPP, polyvinyl polypyrrolidone; ROS, reactive oxygen species; SA, salicylic acid; SAM, S-Adenosylmethionine; SAMDC, S-Adenosylmethionine decarboxylase; SNP, sodium nitroprusside; Spd, spermidine; SPDS, spd synthase; Spm, spermine; SPMS, spm synthase.
}

2008; Groppa et al., 2008; Hussain et al., 2011; Yang et al., 2014).

Nitric oxide is a highly reactive gaseous molecule that regulates a diverse range of physiological processes, including germination, metabolism, transport, flowering, and senescence (Neill et al., 2003; Besson-Bard et al., 2008). In addition, the available evidence indicates that $\mathrm{NO}$ is an important signal molecule involved in multiple plant responses toward a variety of abiotic and biotic stresses (García-Mata and Lamattina, 2001, Hung et al., 2002; Besson-Bard et al., 2008). It is well-established that the exogenous application of $\mathrm{NO}$ can protect plants against stress conditions by promoting growth, PS II) activity, and the maintenance of ionic homeostasis, as well as by activating antioxidant enzymes (Uchida et al., 2002; Shi et al., 2005; Zhang et al., 2006; Ziogas et al., 2015). Furthermore, NO acts in concert with other plant growth regulators, such as ABA and PAs (GarcíaMata and Lamattina, 2001, 2002; Fan et al., 2013; Filippou et al., 2013; Gong et al., 2014); and in Arabidopsis, cucumber, wheat, and soybean, it has been proposed that PAs are able to induce NO generation (Tun et al., 2006; Groppa et al., 2008; Yang et al., 2014). Thus, under conditions of environmental stress, there may be a link between PAs and NO; and this may involve ABA as well.

Several potential NO sources exist in plants, notably the widely known NR and NOS pathway (Desikan et al., 2002; Guo et al., 2003). NR catalyzes the reduction of nitrate to nitrite, using NADH as principal electron donor (Gupta et al., 2011), and this activity is widespread or ubiquitous in higher plants (Desikan et al., 2002; Rockel et al., 2002; Dordas et al., 2003). NOS is responsible for NO synthesis in animals. Although mammaliantype NOS is intricate and a corresponding activity in plants has yet to be fully characterized (Guo et al., 2003; Zemojtel et al., 2006), NOS-like activity has been detected extensively in plants. Moreover, inhibitors of mammalian NOS can inhibit NO production in plants (Neill et al., 2008; Tewari et al., 2013).

Another important signal molecule, $\mathrm{H}_{2} \mathrm{O}_{2}$, is also capable of participating in several physiological processes in plants, including adaptive stress responses (Finkel and Holbrook, 2000; Neill et al., 2003; Bright et al., 2006; Dickinson and Chang, 2011). NADPH oxidases, apoplast amine oxidases, and oxalate oxidase are the main enzymatic sources for the generation of reactive oxygen species (ROS) (Grant and Loake, 2000; Mittler, 2002; Cona et al., 2006). PAs may either trigger ROS synthesis or scavenge ROS, depending on the concentrations of intracellular PAs (Saha et al., 2015). In many cases, the production of $\mathrm{H}_{2} \mathrm{O}_{2}$ via the PA catabolic pathway serves as a protective measure; this process has been well documented (Walters, 2003; Cona et al., 2006). Recent reports also show a relationship between NO and $\mathrm{H}_{2} \mathrm{O}_{2}$. Depending upon the stress conditions, the generation of $\mathrm{NO}$ and $\mathrm{H}_{2} \mathrm{O}_{2}$ may occur either in parallel, or in rapid succession (de Pinto et al., 2002; Bright et al., 2006; Pasqualini et al., 2009).

Abscisic acid is one of the most important phytohormones involved in plant growth, development, and adaptation to a range of stress conditions (Schroeder et al., 2001; Verslues et al., 2006). It has been proposed that 9-cis-epoxycarotenoid dioxygenase 
(NCED) is the rate-limiting enzyme in ABA synthesis (Qin and Zeevaart, 1999; Jahromi et al., 2008). It is well established that PAs, ABA, NO, and $\mathrm{H}_{2} \mathrm{O}_{2}$ are, from a functional perspective, multifaceted molecules, involved in several stress responses in many plant species (Shen et al., 2000; He et al., 2002; Zheng et al., 2009; Yang et al., 2011; Yamamoto et al., 2012; Wang et al., 2013). In our previous study, we observed that both Put and Spd enhanced the chilling tolerance of tomato seedlings (Song et al., 2014b; Diao et al., 2015). It is notable that PAs, ABA, NO, and $\mathrm{H}_{2} \mathrm{O}_{2}$ participate in various physiological and stress responses via a complex network, and that there is an intricate association between them during a plant's response to abiotic stress (Wimalasekera et al., 2011b). To our knowledge, only a small number of studies have examined the potential links between PAs and signal molecules, and PAs and ABA in response to chilling stress in tomato seedlings. Therefore, in this study, we analyzed the effect of PAs on $\mathrm{NO}$ and $\mathrm{H}_{2} \mathrm{O}_{2}$ synthesis in tomato seedlings under chilling stress. At the same time, we examined the changes in PA levels, PA biosynthetic enzymes, and relative gene expression triggered by NO. Furthermore, we investigated the influence of PAs on ABA production under chilling stress.

\section{MATERIALS AND METHODS}

\section{Plant Materials, Growth, and Treatment Conditions}

Plants were grown at Shenyang Agricultural University, Shenyang, China. Seeds of tomato (Lycopersicon esculentum Mill. $\mathrm{cv}$. Moneymaker) were germinated in 50-hole plates containing peat moss. When the seedlings had developed two true leaves, they were transplanted into $12 \mathrm{~cm} \times 12 \mathrm{~cm}$ plastic trays filled with peat moss in a greenhouse (average day/night temperature, $25^{\circ} \mathrm{C} / 15^{\circ} \mathrm{C}$ ) with natural light at a relative humidity of $60 \%$ and watered daily. Seedlings were used for experiments at the five-leaf stage.

To investigate the effects of exogenous PAs, seedlings were subjected to four treatments: (1) $\mathrm{H}_{2} \mathrm{O}+$ chilling (as control); (2) $1 \mathrm{mM}$ Put+chilling; (3) $1 \mathrm{mM} \mathrm{Spd+chilling;} \mathrm{and} \mathrm{(4)} 1 \mathrm{mM}$ Spm+chilling. The leaves of the tomato seedlings were sprayed completely with $1 \mathrm{mM}$ Put, $1 \mathrm{mM}$ Spd, or $1 \mathrm{mM} \mathrm{Spm}$ once each day for a week. Following transfer to a phytotron, the seedlings were then subjected to chilling stress. The environmental conditions were: photosynthetic photon flux density (PPFD), $600 \mu \mathrm{molm}^{-2} \mathrm{~s}^{-1}$; temperatures, $4^{\circ} \mathrm{C}$. Samples were taken at 0,12 , and $24 \mathrm{~h}$ for physiological and biochemical analyses (including determinations of $\mathrm{NO}$ and $\mathrm{H}_{2} \mathrm{O}_{2}$ levels, $\mathrm{DAO}$ and PAO activities, NR activity, NOS-like activities, and relative gene expressions). After $24 \mathrm{~h}$ of chilling stress treatment, seedlings were maintained under $25^{\circ} \mathrm{C} / 15^{\circ} \mathrm{C}$ conditions for a further $10 \mathrm{~h}$ for recovery.

In order to investigate the relationship between $\mathrm{NO}$ and $\mathrm{H}_{2} \mathrm{O}_{2}$ induced by Spd, before chilling treatment $\left(4^{\circ} \mathrm{C}\right)$, some seedlings were treated by spraying with $200 \mu \mathrm{M} \mathrm{N} \mathrm{N}^{\mathrm{G}}$-nitro-L-arginine methyl ester $\mathrm{HCl}$ (L-NAME, an inhibitor of NOS), $200 \mu \mathrm{M}$ tungstate (an inhibitor of NR), and $200 \mu \mathrm{M}$ PTIO (2-phenyl4,4,5,5-tetramethylimidazoline-1-oxyl-3-oxide, a scavenger of $\mathrm{NO})$ prior to the Spd+chilling treatment. Other seedlings were treated by spraying with $100 \mu \mathrm{M}$ DPI (2,6-DPI, a NADPH oxidase inhibitor) and $5 \mathrm{mM}$ DMTU (dimethylthiourea, a $\mathrm{H}_{2} \mathrm{O}_{2}$ and $\mathrm{OH}$. scavenger), In each case, the pre-treatment was carried out for $12 \mathrm{~h}$ daily (from 18:00 until 06:00) for 3 days. The seedlings were then sprayed with $1 \mathrm{mM}$ Spd, $12 \mathrm{~h}$ after the final treatment. Seedlings sprayed with distilled water and subjected to chilling at $4^{\circ} \mathrm{C}$ and at a PPFD of $600 \mu \mathrm{molm}^{-2} \mathrm{~s}^{-1}$ served as the control. Leaves were harvested for $\mathrm{NO}$ and $\mathrm{H}_{2} \mathrm{O}_{2}$ analyses $24 \mathrm{~h}$ after the chilling treatments.

To investigate whether NO induced PAs, prior to chilling stress treatment seedlings were sprayed with $200 \mu \mathrm{M}$ SNP (a NO donor). Leaves were then harvested following 0,12 , and $24 \mathrm{~h}$ of chilling treatment, and in addition after $10 \mathrm{~h}$ of recovery at $25^{\circ} \mathrm{C} / 15^{\circ} \mathrm{C}$, for determination of PAs and analyses of relative gene expression.

To investigate the effect of Put on endogenous $A B A$, prior to chilling stress treatment $\left(4^{\circ} \mathrm{C}\right)$, seedlings were sprayed with $1 \mathrm{mM}$ D-arginine (D-Arg) (an inhibitor of Put synthesis), and then treated with Put or distilled water $12 \mathrm{~h}$ later. Leaves were harvested following 0,12 , and $24 \mathrm{~h}$ of chilling treatment, for analyses of ABA levels and LeNCED1 expression.

To investigate the effect of $A B A$ on EL, seedlings were sprayed with $1 \mathrm{mM} \mathrm{ABA}$ and $1 \mathrm{mM} \mathrm{D}$-Arg, separately, and then $12 \mathrm{~h}$ afterward were exposed to chilling stress $\left(4^{\circ} \mathrm{C}\right)$ for $24 \mathrm{~h}$. Other seedlings were sprayed with $1 \mathrm{mM} \mathrm{D}$-Arg alone; after $12 \mathrm{~h}$, these were then sprayed with $1 \mathrm{mM} \mathrm{ABA}$ and exposed to chilling stress for $24 \mathrm{~h}$.

For each of these treatments, seedlings sprayed with distilled water in place of the respective reagents, but otherwise treated identically, served as controls.

For all treatments described, the third and fourth fully expanded leaves from 12 uniform seedlings were used for analysis. The leaves were repeatedly washed in deionized distilled water, and then frozen in liquid nitrogen and stored at $-80^{\circ} \mathrm{C}$ prior to analysis.

\section{PA Determination}

Free PAs were quantified by the method of Duan et al. (2008), with slight modifications. Leaves $(0.5 \mathrm{~g})$ were homogenized in $3 \mathrm{~mL}$ of chilled $0.5 \%(\mathrm{w} / \mathrm{v})$ perchloric acid (PCA), kept on ice for $1 \mathrm{~h}$, and then centrifuged at $12,000 \times g$ and $4^{\circ} \mathrm{C}$ for $20 \mathrm{~min}$. The supernatant $(500 \mu \mathrm{L})$ was then mixed with $1 \mathrm{~mL}$ of $2 \mathrm{M} \mathrm{NaOH}$ and $7 \mu \mathrm{L}$ of benzoyl chloride. The mixture was vortexed for $20 \mathrm{~s}$, and then incubated for $30 \mathrm{~min}$ at $37^{\circ} \mathrm{C}$. Saturated $\mathrm{NaCl}(2 \mathrm{~mL})$ was then added and the benzoyl PAs were extracted with $2 \mathrm{~mL}$ of diethyl ether. The sample was then centrifuged at $1,500 \times g$ for $5 \mathrm{~min}$. Finally, $1 \mathrm{~mL}$ of the ether phase was taken, the ether was evaporated and the residue was re-dissolved in $100 \mu \mathrm{L}$ of methanol. PA standards were prepared as described for leaf samples. The content of PAs was analyzed by HPLC (Waters 600, Waters Co., Ltd, USA). PAs were separated on a reverse-phase C-18 column eluted at room temperature using $60 \%(\mathrm{v} / \mathrm{v})$ methanol at a flow rate of 
$0.8 \mathrm{~mL} / \mathrm{min}$. The absorbance at $254 \mathrm{~nm}$ was measured using a $\mathrm{UV}$-vis detector.

\section{ABA Determination}

Abscisic acid was extracted and measured according to LopezCarbonell and Jauregui (2005). Leaf samples (0.5 g) were homogenized at $-20^{\circ} \mathrm{C}$ in acetone:water:acetic acid (80:19:1, $\mathrm{v} / \mathrm{v})$, vortexed, and centrifuged at $10,000 \times g$ and $4^{\circ} \mathrm{C}$ for $10 \mathrm{~min}$. The supernatants were collected and the pellets reextracted with extraction solvent. The second extraction was centrifuged, and then the first and second supernatants were combined and dried under a nitrogen stream. The dried samples were kept at $-20^{\circ} \mathrm{C}$. Immediately prior to analysis, the extracts were re-dissolved in $200 \mu \mathrm{L}$ of water:acetonitrile:acetic acid (90:10:0.05, v/v/v), stirred, vortexed, cleared by centrifugation at $10,000 \times g$ for $5 \mathrm{~min}$, and then filtered through a $0.45-\mu \mathrm{m}$ polytetrafluoroethylene filter. ABA was determined by HPLC (Waters 600, Waters Co., Ltd, USA) at $30^{\circ} \mathrm{C}$, using a 4.6 $\mathrm{mm} \times 250-\mathrm{mm}$ reverse-phase C-18 column, with elution by a linear gradient of $0.05 \%(\mathrm{w} / \mathrm{v})$ acetic acid in water (solvent $\mathrm{A}$ ) and acetonitrile at a flow rate of $0.4 \mathrm{ml} / \mathrm{min}^{-1}$. The gradient profile $[t(\min ), \% \mathrm{~A}]$ was: $(0,85),(5,0),(5.2,0),(6,85),(10$, 85). The absorbance at $262 \mathrm{~nm}$ was measured using a UV-vis detector.

\section{Determination of NO}

Nitric oxide content was determined as described by Murphy and Noack (1994), with some modifications. Leaf samples (0.5 g) were incubated for $5 \mathrm{~min}$ with $100 \mathrm{U}$ of catalase and $100 \mathrm{U}$ of superoxide dismutase to remove endogenous ROS, prior to the addition of $10 \mathrm{~mL}$ of $5 \mathrm{mM}$ oxyhemoglobin $\left(\mathrm{HbO}_{2}\right)$. After 2 min, $\mathrm{NO}$ was determined spectrophotometrically by measuring the conversion of $\mathrm{HbO}_{2}$ to methemoglobin (metHb), and the NO content was calculated using an extinction coefficient of $77 \mathrm{mM}^{-1} \mathrm{~cm}^{-1}\left[A_{401}(\operatorname{metHb})-A_{421}\left(\mathrm{HbO}_{2}\right)\right]$.

\section{Fluorescent Detection of NO}

Nitric oxide was detected using the fluorescent dye DAF-FM DA (Sigma). Epidermal fragments of tomato were placed in $1 \mathrm{ml}$ of DAF-FM DA buffer solution (10 mM Tris-HCl, $\mathrm{pH}$ 7.2) and were then incubated for $20 \mathrm{~min}$ at room temperature with $1 \mathrm{ml}$ of $5 \mu \mathrm{M}$ DAF-FM DA in $10 \mathrm{mM}$ Tris-HCl buffer ( $\mathrm{pH}$ 7.2). The incubation solutions were then pipetted off. After washing with fresh loading buffer three times, the epidermal fragments were mounted on a microscope slide in the same medium for examination with a Zeiss Axiovert $200 \mathrm{M}$ inverted microscope equipped with a confocal laser scanner (Zeiss LSM 510). Excitation and emission were at 495 and $515 \mathrm{~nm}$, respectively. Images were processed and analyzed using Zeiss 2012 software.

\section{Determination of $\mathrm{H}_{2} \mathrm{O}_{2}$}

Hydrogen peroxide content was quantified by the method of Patterson et al. (1984), with some modifications. Leaf samples $(0.5 \mathrm{~g})$ were homogenized in $3 \mathrm{~mL}$ of ice-cold acetone. Titanium reagent $(20 \% \mathrm{v} / \mathrm{v}$ titanic tetrachloride in concentrated $\mathrm{HCl})$ was then added to $1 \mathrm{~mL}$ of extract supernatant. The Ti$\mathrm{H}_{2} \mathrm{O}_{2}$ complex was then precipitated by adding $0.2 \mathrm{~mL}$ of $17 \mathrm{M}$ ammonia solution and centrifuging at $30,000 \times g$, for $10 \mathrm{~min}$ at $4^{\circ} \mathrm{C}$, the supernatant being discarded. The pellet was washed three times by centrifugation and resuspension in icecold acetone, and finally dissolved in $3 \mathrm{~mL}$ of $1 \mathrm{M} \mathrm{H}_{2} \mathrm{SO}_{4}$. The absorbance of the solution was measured at $410 \mathrm{~nm}$ and an extinction coefficient of $0.28 \mathrm{mM}^{-1} \mathrm{~cm}^{-1}$ was used for calculation.

\section{Histochemical Detection of $\mathrm{H}_{2} \mathrm{O}_{2}$}

Hydrogen peroxide was detected visually by using 3,-3diaminobenzidine (DAB) staining method according to Orozoco-Cardenas and Ryan (1999), with some modifications. Leaves of seedlings subjected to different treatments were immersed in a $1 \mathrm{mg} \mathrm{mL}^{-1}$ solution of DAB (Sigma) and then vacuum-infiltrated for $30 \mathrm{~min}$. After incubation for $9 \mathrm{~h}$ at $25^{\circ} \mathrm{C}$, the leaves were decolorized in $95 \%$ ethanol at $80^{\circ} \mathrm{C}$ for $30 \mathrm{~min}$, and then photographed.

\section{Determination of DAO and PAO Activities}

Diamine oxidase and PAO activities were measured by the method of Song et al. (2014a). Leaf samples (0.5 g) were homogenized in chilled potassium phosphate buffer (0.1 $\mathrm{mol} \cdot \mathrm{L}^{-1}, \mathrm{pH}$ 6.5). The homogenate was centrifuged at $10,000 \times g$, for $20 \mathrm{~min}$ at $4^{\circ} \mathrm{C}$. The supernatant was then used for the assay of DAO and PAO.

\section{Determination of NR Activity}

Nitrite reductase activity was determined according the method of Scheible et al. (1997), with some modifications. Leaf samples $(0.5 \mathrm{~g})$ were first homogenized in chilled extraction buffer comprising $100 \mathrm{mM}$ HEPES-KOH, $\mathrm{pH}$ 7.5, $5 \mathrm{mM}$ dithiothreitol, $1 \mathrm{mM}$ EDTA, $10 \%$ (v/v) glycerol, $0.1 \%$ (w/v) Triton X100, $0.5 \mathrm{mM}$ PMSF, $1 \mu \mathrm{M}$ leupeptin, $20 \mu \mathrm{M}$ flavin adenine dinucleotide (FAD), $5 \mu \mathrm{M} \mathrm{Na} \mathrm{MoO}_{4}$, and $1 \%$ (w/v) PVPP, and then centrifuged at $10,000 \times g$ and $4^{\circ} \mathrm{C}$ for $20 \mathrm{~min}$. One volume of supernatant was then mixed with five volumes of assay buffer (100 mM HEPES-KOH, pH 7.5, $5 \mathrm{mM} \mathrm{KNO}_{3}$, and $0.25 \mathrm{mM} \mathrm{NADH})$. The reaction was started by the addition of assay buffer, incubated at $25^{\circ} \mathrm{C}$ for $30 \mathrm{~min}$, and then stopped by adding $0.1 \mathrm{M}$ zinc acetate. After $15 \mathrm{~min}$, the stopped reaction mixture was centrifuged at $13,000 \times g$ for $5 \mathrm{~min}$. The supernatant was then added to sulfanilamide $(1 \%$, $\mathrm{v} / \mathrm{v}$, in $3 \mathrm{M} \mathrm{HCl})$ and $N$-1-naphthylethylenediamine $(0.02 \%$, $\mathrm{w} / \mathrm{w})$. The nitrite produced was measured colorimetrically at $520 \mathrm{~nm}$.

\section{Determination of NOS-Like Activity}

The NOS-like activity was assayed using a NOS colorimetric assay kit (Nanjing Jiancheng Bioengineering Institute, Jiangsu, China). Leaf samples $(0.5 \mathrm{~g})$ were homogenized in $2 \mathrm{~mL}$ of $50 \mathrm{mM}$ phosphate-buffered saline, $\mathrm{pH} 7.4$, containing $1.0 \mathrm{mM}$ leupeptin, 1.0 mM EDTA, $10.0 \mathrm{mM}$ ethyleneglycol bis (2aminoethyl ether) tetraacetic acid, $1.0 \mathrm{mM}$ PMSF and $10 \mathrm{~g}$ $\mathrm{L}^{-1}$ PVPP. After centrifuging at $15,000 \times g$ for $20 \mathrm{~min}$, the 
supernatant was incubated with the kit assay reagent for $15 \mathrm{~min}$ at $37^{\circ} \mathrm{C}$ and the reaction was then terminated using the stop buffer from the NOS assay kit. The absorbance was measured at $530 \mathrm{~nm}$.

\section{Determination of Electrolyte Leakage}

Electrolyte leakage was determined according to Sairam and Srivastava (2002). Leaf samples $(0.2 \mathrm{~g})$ were rinsed three times with deionized water, and then kept in $20 \mathrm{ml}$ of distilled water at $25^{\circ} \mathrm{C}$ for $3 \mathrm{~h}$. The electrical conductivity of the solution (initial electrical conductivity E1) was then measured. The solution containing the leaves was then boiled at $100^{\circ} \mathrm{C}$ for $30 \mathrm{~min}$ to release all electrolytes, cooled to $25^{\circ} \mathrm{C}$, and the final electrical conductivity (E2) was measured. The relative EL was calculated as E1/E2 and expressed as a percentage.

\section{Total RNA Extraction and Gene Expression Analysis}

Total RNA was extracted using an RNAprep pure plant total RNA extraction kit (Kangwei, Beijing, China). DNA contamination was eliminated by adding RQ1 DNAse (Promega). Total RNA concentrations of samples were routinely determined from $A_{260}$ and $A_{280}$ values and integrity was checked by agarose gel electrophoresis.

RNA samples were reverse-transcribed into cDNAs according to the kit manufacturer's instructions (Tiangen Biotech Co. Ltd, Beijing, China). The resulting cDNAs were used as templates for PCR amplification. To confirm accuracy, all PCR products of the expected size were sequenced (Sangon Biotech Co. Ltd, Shanghai, China).

Primers were designed using Primer Express 3.0 software. The PCR primer sequences are listed in Table 1. Real-time PCR analysis was performed as follows. The cDNA samples were used as the template and mixed with $200 \mathrm{nmol}$ of each primer and SYBR Green PCR Real Master Mix (Tiangen Biotech Co. Ltd, Beijing, China) for real-time PCR analysis using an ABI 7500 (Applied Biosystems, USA). To determine relative gene expression for each sample, the threshold cycle $\left(C_{\mathrm{t}}\right)$ value was normalized to actin and set relative to control samples according to the $2^{-\Delta \Delta C t}$ method.

\section{Statistical Analysis}

Two independent experiments were performed, with three replicates for each treatment. Data were analyzed using Duncan's multiple range test at a 0.05 significance level. The charts were compiled using the Origin program (version 8.0).

\section{RESULTS}

\section{Effects of Exogenous PAs on Endogenous NO Biosynthesis Pathway in Tomato Leaves under Chilling Stress}

As shown in Figure 1A, in control seedlings, chilling stress induced a slight release of NO at 12 and $24 \mathrm{~h}$; however, after the recovery treatment, this effect was not observed. Compared to the control, treatment with Put did not induce any obvious change in $\mathrm{NO}$ accumulation throughout the treatment period. In contrast, exogenous application of Spd or Spm induced a significantly higher production of $\mathrm{NO}$ at $12 \mathrm{~h}$ and $24 \mathrm{~h}$ of chilling stress than in the control, but this effect was not sustained following the recovery period (Figure $\mathbf{1 A}$ ).

Nitrite reductase activity increased under chilling stress both in control and in Put-treated seedlings, with no significant difference between them. However, chilling-stressed plants that had been treated with Spd showed a dramatic increase in NR activity relative to control seedlings after 12 and $24 \mathrm{~h}$ of chilling stress. Similar results were observed for Spm treatment. None of the three PA treatments appreciably altered the NR activity relative to the control during the recovery time, however (Figure 1B).

Nitric oxide synthase-like activity was not induced by Put treatment, relative to the control, at any time during the entire treatment and recovery period. In Spd- and Spm-treated plants, on the other hand, NOS-like activity was significantly increased, relative to the control, after 12 and $24 \mathrm{~h}$ of stress treatment. None of the PAs had any effect on the levels of NOS-like activity during the recovery time (Figure $\mathbf{1 C}$ ).

In tomato, NR and NOS-like activities are encoded by the genes LeNR and LeNOS1, respectively. In the present study, compared to the control, exogenous Put did not alter LeNR transcript levels throughout the period of treatment. In contrast,

TABLE 1 | Nitric oxide-interrelated genes and PAs biosynthetic enzyme genes accession numbers and primer sequences of the genes described in this study.

\begin{tabular}{|c|c|c|c|}
\hline Category & Accession & Encode corresponding enzyme & Primer sequences $\left(5^{\prime}-3^{\prime}\right)$ \\
\hline LeADC & HM629957 & ADC & F5' - TGCTTGAAGTGTCTCTTG -3'R5' - GATTGCGGTCATAACATAAG -3' \\
\hline LeADC1 & NM_001247135 & ADC & F5' - CACAAGGAAGAAGAAGTAGA -3'R5' - GCCAACACCAACAATATTC -3' \\
\hline LeODC & NM_001247687 & ODC & F5' - TAAGGGATTACCAGTTACC -3'R5' - GGATAAGCATAAGCAAGG -3' \\
\hline LeSAMDC & EF550528 & SAMDC & F5'- GACTTGCCAGTITCTGCCA -3’R5' - CGGACAGCACATAGGAATCAA -3' \\
\hline LESPDS & NM_001247564 & SPDS & F5' - TGGAGGCAGCCAATAACA -3'R5' - CCTTCCCATAAGTTGATGACTG -3' \\
\hline LeSPMS & AY335900 & SPMS & F5' - GAGAAGCACATTCCCTGAAAG -3'R5' - AGAACTCCACCATCACCACC -3' \\
\hline LeNR & HQ616893 & NR & F5'-ATCACCCAGAGAAGCCAACA-3'R5'-GAGGGTCTCATCGGTAGCTC-3' \\
\hline LeNOS1 & XM_004235117 & NOS & F5'-GAGCTCCGTTACACACATCG-3'R5' -CGACACCGTCCACAAAGAAT-3' \\
\hline LeNCED1 & AJ439079.2 & NCED & F5'-GAACTTCGTCGTCATTCCTG-3'R5' - CATCTITCGCGTACTTATCCA-3' \\
\hline Actin & Q96483 & Reference gene & F5' - GAGAAGCACATTCCCTGAAAG -3'R5' - AGAACTCCACCATCACCACC -3' \\
\hline
\end{tabular}



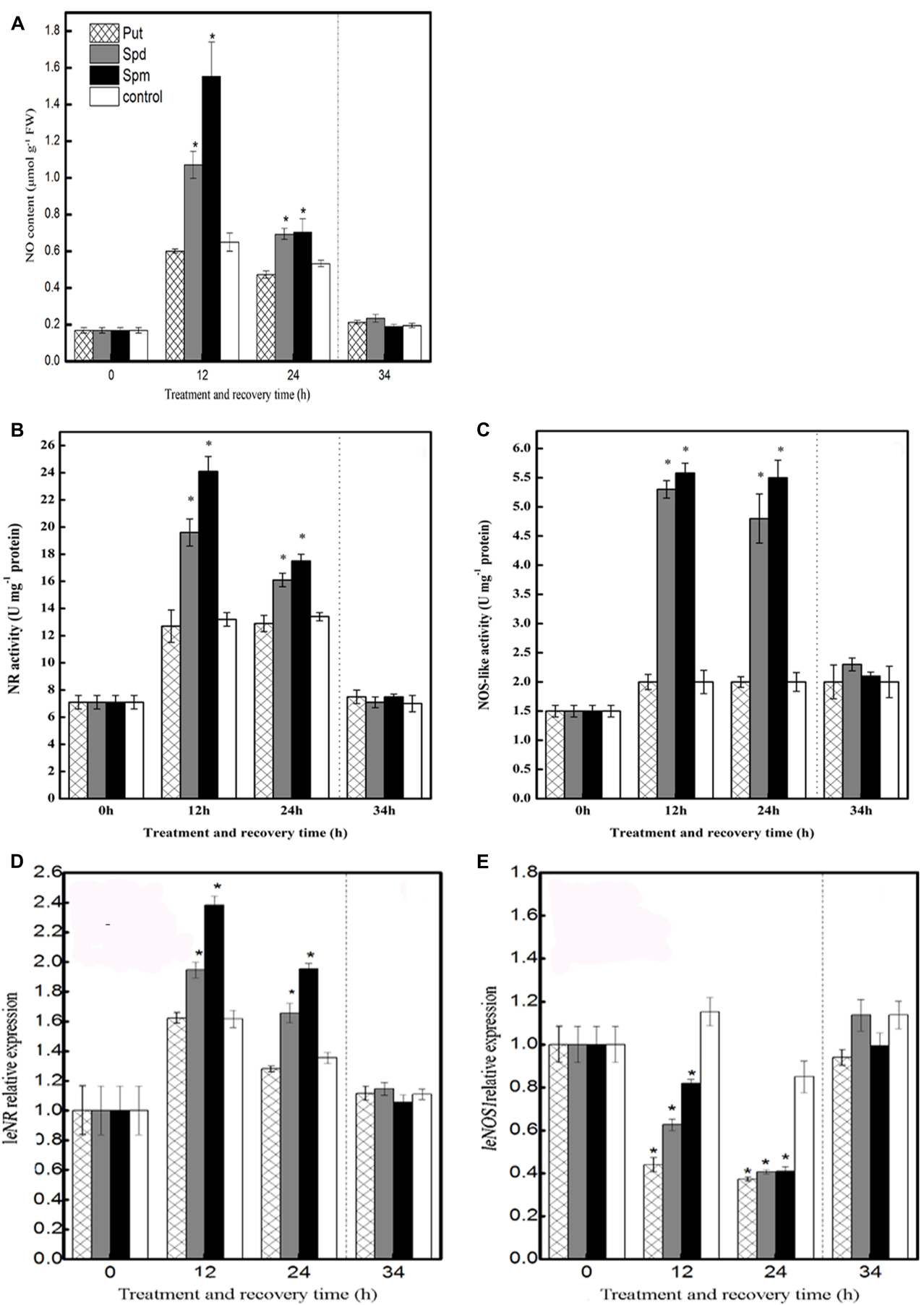

FIGURE 1 | Effect of exogenous PAs on NO biosynthesis pathway. (A) NO content, (B) NR activity, (C) NOS-like activity, (D) NR relative expression, and (E) NOS1 relative expression in the leaves of tomato under chilling stress and recovery period. Seedlings were treated with PAs (1 $\mathrm{mM}$ Put, $1 \mathrm{mM}$ Spd, and $1 \mathrm{mM}$ $\mathrm{Spm}$ ) or distilled water (control). The samples were harvested for analysis of $\mathrm{NO}$ content during chilling stress $\left(4^{\circ} \mathrm{C}\right.$; 0 , 12, and $\left.24 \mathrm{~h}\right)$ and recovery treatment $\left(25^{\circ} \mathrm{C}\right.$; $10 \mathrm{~h}$ ). Data represent the mean $\pm \mathrm{SE}$ of three independent experiments and asterisks represent significant differences compared to control at $P \leq 0.05$ according to Duncan's multiple range test.

Spd treatment increased LeNR transcript levels significantly after 12 and $24 \mathrm{~h}$ of chilling stress, compared to the levels in the control, and the transcript levels peaked at $12 \mathrm{~h}$ of the treatment. Thereafter, however, LeNR expression during the recovery period was scarcely affected relative to the control. The effects of Spm were similar to those of Spd; again, no significant change was observed in the level of LeNR transcript during the recovery period (Figure 1D). 
In the case of LeNOS1, the application of Put, Spd, or Spm reduced expression, relative to the control. during the chilling-stress period; however, expression during the subsequent recovery period was not appreciably affected (Figure 1E).

\section{Effects of Exogenous PAs on Endogenous $\mathrm{H}_{2} \mathrm{O}_{2}$ Production and PAs Degradative Enzymes Activities in Tomato Leaves under Chilling Stress}

Chilling stress induced $\mathrm{H}_{2} \mathrm{O}_{2}$ accumulation at 12 and $24 \mathrm{~h}$ in control seedlings, though this effect did not persist during the subsequent recovery period. This accumulation of $\mathrm{H}_{2} \mathrm{O}_{2}$ at 12 and $24 \mathrm{~h}$ was greatly increased in seedlings treated with Spd or Spm, but not in seedlings treated with Put. None of the three PAs had any significant effect on $\mathrm{H}_{2} \mathrm{O}_{2}$ levels during the subsequent recovery period (Figure 2A).
Seedlings treated with Spd and Spm showed significantly increased activities of DAO and PAO, relative to control seedlings, at 12 and $24 \mathrm{~h}$ of stress treatment, but this effect did not persist into the recovery period. Treatment with Put barely had essentially no effect on DAO and PAO activities throughout the treatment period (Figures 2B,C).

\section{Effects of $\mathrm{H}_{2} \mathrm{O}_{2}$ Inhibitor and Scavenger on Spd-induced NO Production in Tomato Leaves under Chilling Stress}

Both the fluorescence detection of $\mathrm{NO}$ and its spectrophotometric determination suggested that, relative to control seedlings, treatment with Spd significantly induced NO accumulation during subsequent chilling stress. Compared to treatment with Spd alone, treatment with Spd together with DPI (a NADPH oxidase inhibitor) and DMTU $\left(\mathrm{a}_{2} \mathrm{O}_{2}\right.$ and
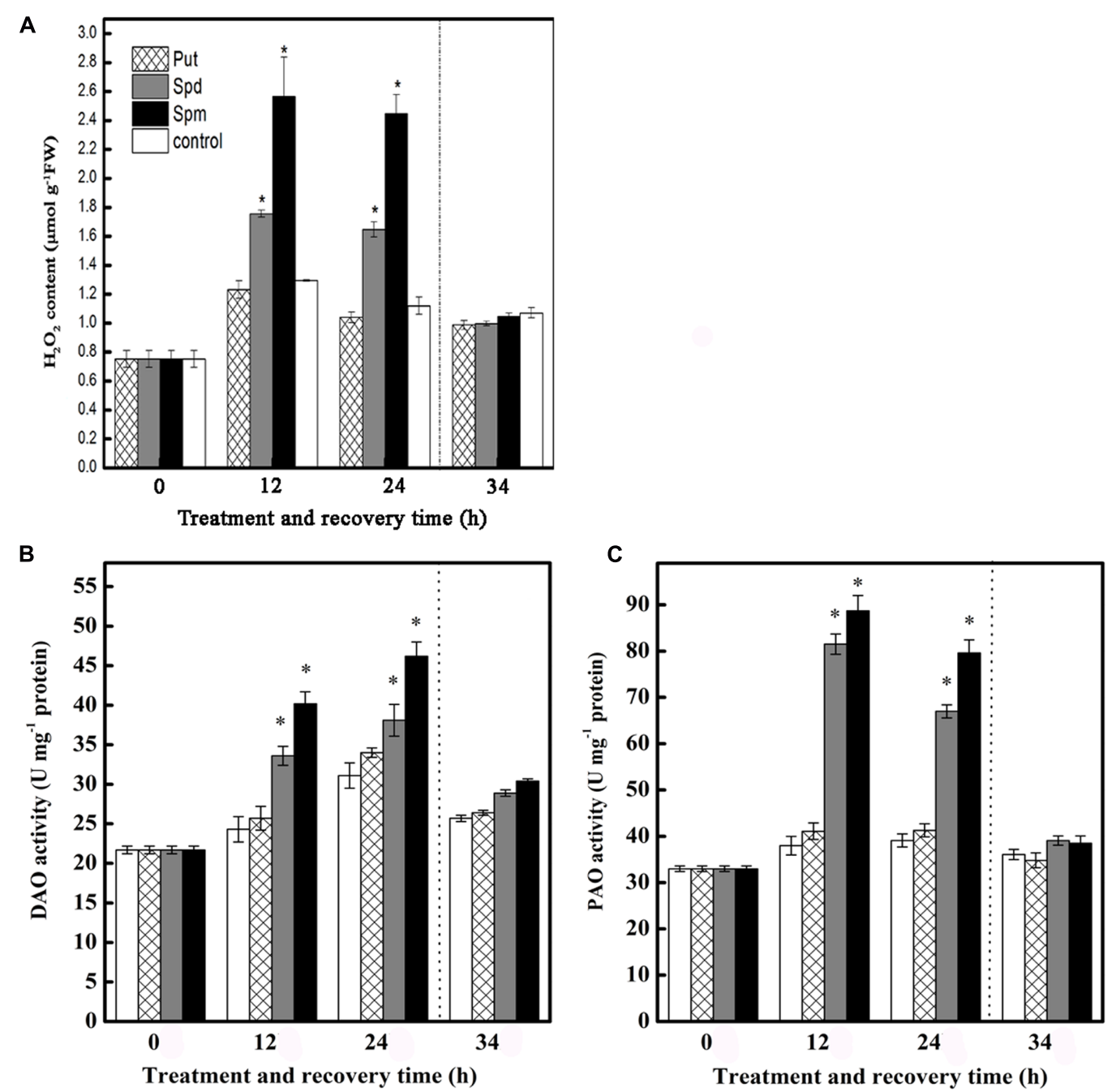

FIGURE 2 | Effect of exogenous PAs on (A) $\mathrm{H}_{2} \mathrm{O}_{2}$ content, (B) DAO activity, and (C) PAO activity in the leaves of tomato under chilling stress. The treatment details are as in the Figure 1. Data represent the mean \pm SE of three independent experiments and asterisks represent significant differences compared to control at $P \leq 0.05$ according to Duncan's multiple range test. 
$\mathrm{OH}^{\bullet}$ scavenger) greatly reduced the effect of Spd (Figures $3 \mathbf{A}, \mathbf{B}$ ), suggesting that $\mathrm{H}_{2} \mathrm{O}_{2}$ can participate in Spd-induced NO production during chilling stress.

\section{Effect of NO Inhibitor and Scavenger on Spd-induced $\mathrm{H}_{2} \mathrm{O}_{2}$ Generation in Tomato Leaves under Chilling Stress}

As shown in Figure 4A, treatment with Spd dramatically enhanced the $\mathrm{H}_{2} \mathrm{O}_{2}$ content in chilling-treated seedlings. In contrast, when tungstate (an inhibitor of NR), L-NAME (an inhibitor of NOS), and PTIO (a scavenger of NO) were applied in advance of the Spd treatment, $\mathrm{H}_{2} \mathrm{O}_{2}$ levels were barely increased. This finding was confirmed histochemically using DAB staining for detection of $\mathrm{H}_{2} \mathrm{O}_{2}$ (Figure 4B).

\section{Effects of Exogenous NO on Free Endogenous PAs Contents in Tomato Leaves under Chilling Stress}

As shown in Figure $\mathbf{5 A}$, application of SNP led to a dramatic increase in leaf free Put content at $12 \mathrm{~h}$ of chilling stress, relative to control seedlings, but no obvious effect was detected at $24 \mathrm{~h}$. However, during the recovery period, the leaves of seedlings treated with SNP showed a free Put content that was 91.5\% higher than that of control leaves.

Compared to the control, SNP had no pronounced effect on free Spd content at $12 \mathrm{~h}$ of chilling stress; however, at $24 \mathrm{~h}$ and during the recovery period, SNP clearly enhanced free Spd content, relative to the control values, by about 20.9 and $36.9 \%$, respectively (Figure 5B).

In contrast to its effects on free Put and free Spd, SNP barely changed the free Spm content throughout the treatment period, indicating that exogenous SNP had little effect on free Spm levels (Figure 5C).

\section{Effects of Exogenous NO on Gene Expressions of PAs Biosynthetic Enzymes in Tomato Leaves under Chilling Stress}

As shown in Figure 6, application of SNP significantly increased the expression of $L e O D C, L e A D C$, and LeADC1 at $12 \mathrm{~h}$ of chilling-stress treatment, relative to control seedlings, but had little effect on LeSAMDC, LeSPDS, and LeSPMS transcript levels. With the exception of an increase in LeSPDS expression, similar results were obtained at $24 \mathrm{~h}$. On the other hand, during the recovery period, exogenous SNP upregulated the expression of LeODC, LeADC, LeADC1, and LeSPDS, but scarcely affected the expression of LeSAMDC and LeSPMS (Figure 6).

\section{Effects of Exogenous Put and D-Arg on ABA Content in Tomato Leaves under Chilling Stress}

As shown in Figure 7A, In control seedlings, chilling stress significantly increased the leaf ABA content at both 12 and $24 \mathrm{~h}$. This effect was increased in Put-treated seedlings. This effect of Put was substantially reduced by treatment with D-Arg (Put

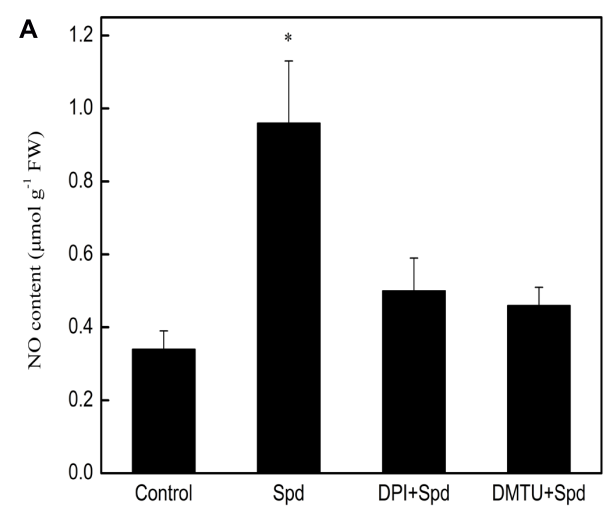

B
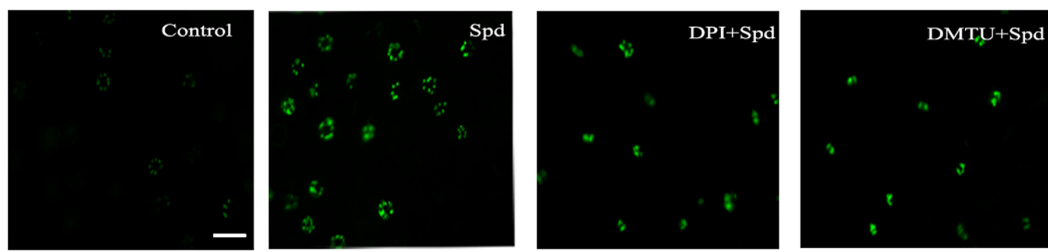

FIGURE 3 | Effect of DPI and DMTU on Spd-induced NO production in the leaves of tomato under chilling stress (4 $\left.{ }^{\circ} \mathrm{C}, 24 \mathrm{~h}\right)$. (A) NO content, (B) fluorescence imagines of NO. Scale bar for NO accumulation represents $60 \mu \mathrm{M}$. Four treatments were used: (1) control; (2) 1 mM Spd; (3) $100 \mu \mathrm{M} \mathrm{DPI+1} \mathrm{mM} \mathrm{Spd;}$ (4) $5 \mathrm{mM}$ DMTU $+1 \mathrm{mM}$ Spd. Data represent the mean \pm SE of three independent experiments and asterisks represent significant differences compared to control at $P \leq 0.05$ according to Duncan's multiple range test. 


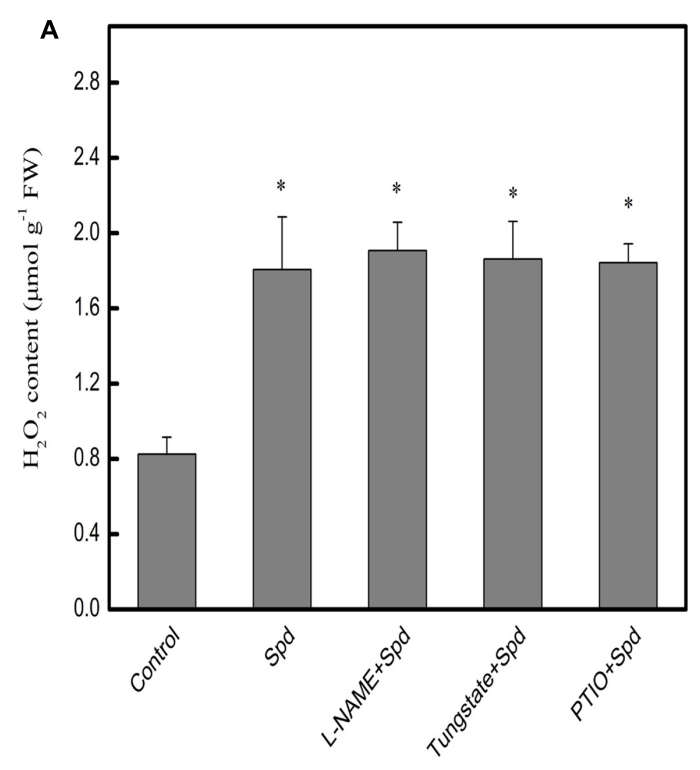

B

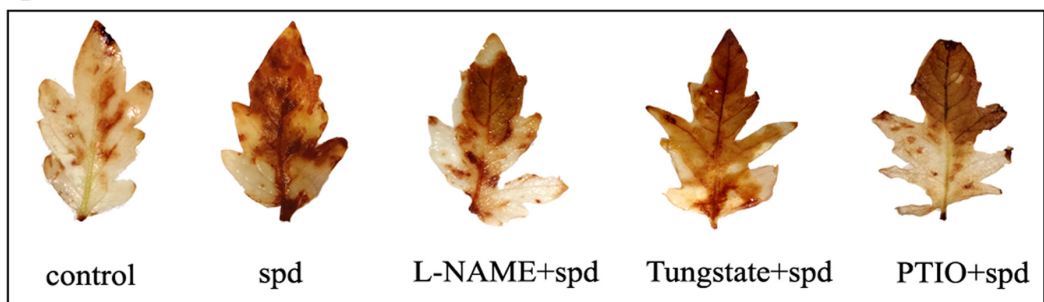

FIGURE 4 | Effect of different treatments on Spd-induced $\mathbf{H}_{\mathbf{2}} \mathrm{O}_{\mathbf{2}}$ generation in the leaves of tomato under chilling stress (4 ${ }^{\circ} \mathbf{C}, 24 \mathbf{~ h ) . ~ ( A ) ~} \mathrm{H}_{2} \mathrm{O}_{2}$ content, (B) detection of $\mathrm{H}_{2} \mathrm{O}_{2}$ by DAB staining. Five treatments were used: (1) control; (2) 1 mM Spd; (3) $200 \mu \mathrm{M} \mathrm{L-NAME+1} \mathrm{mM} \mathrm{Spd;} \mathrm{(4)} 200 \mu \mathrm{M}$ Tungstate+1 mM Spd; (5) $200 \mu \mathrm{M} \mathrm{PTIO}+1 \mathrm{mM}$ Spd. Data represent the mean \pm SE of three independent experiments and asterisks represent significant differences compared to control at $P \leq 0.05$ according to Duncan's multiple range test.

biosynthesis inhibitor). A significant decrease in ABA levels, relative to control seedlings, was observed during chilling stress in $\mathrm{D}$-Arg-treated seedlings.

As shown in Figure 7B, increased LeNCED1 expression was observed in control seedlings under chilling stress. In Put-treated seedlings, this effect was greatly enhanced. In contrast, treatment with D-Arg reduced the expression of LeNCED1 relative to that in control seedlings. This effect of D-Arg was offset in Put-treated seedlings.

\section{Effects of Exogenous ABA and D-Arg on Electrolyte Leakage in Tomato Leaves under Chilling Stress}

Compared to the control, chilling stress markedly increased EL. Application of ABA dramatically decreased this effect, whereas in contrast. Treatment with D-Arg enhanced it. The effect of D-Arg could be offset by the application of ABA (Figure 8).

\section{DISCUSSION}

It is well established that $\mathrm{NO}$ is a bioactive signaling molecule that is widespread in living organisms. Not only is NO involved in the regulation of plant growth and development, but it also plays an important role in the response of plants to abiotic and biotic stresses (García-Mata and Lamattina, 2001; Neill et al., 2003; Zhao et al., 2004). In some cases, it is probably associated with an antioxidative function (Lamattina et al., 2003; Laspina et al., 2005). It is also likely that the protective effects of NO can be achieved through influencing the expression of defenserelated genes and the defense signaling cascade (Neill et al., 2003). Besides the interplay of NO with other signals, NO is also linked with phytohormones (Huang et al., 2004; Zhou et al., 2005). For example, Zhang et al. (2007) indicated that NO participates in enhancing the ABA-induced antioxidant capability in maize. Moreover, because of the common precursor L-arginine, NO has a connection with PAs. Results obtained in Arabidopsis revealed that the NO induced by PAs had a key role in alleviating stress injury (Tun et al., 2006). To elucidate the impact of exogenous PAs on NO production in tomato seedlings under chilling stress, we monitored the NO content in leaves. Our results showed that, throughout the treatment period, the application of Put had no clear effect on NO accumulation. In contrast, both Spd and Spm treatment significantly enhanced NO production under chilling stress, although no obvious difference relative to the control was observed during the subsequent recovery period 

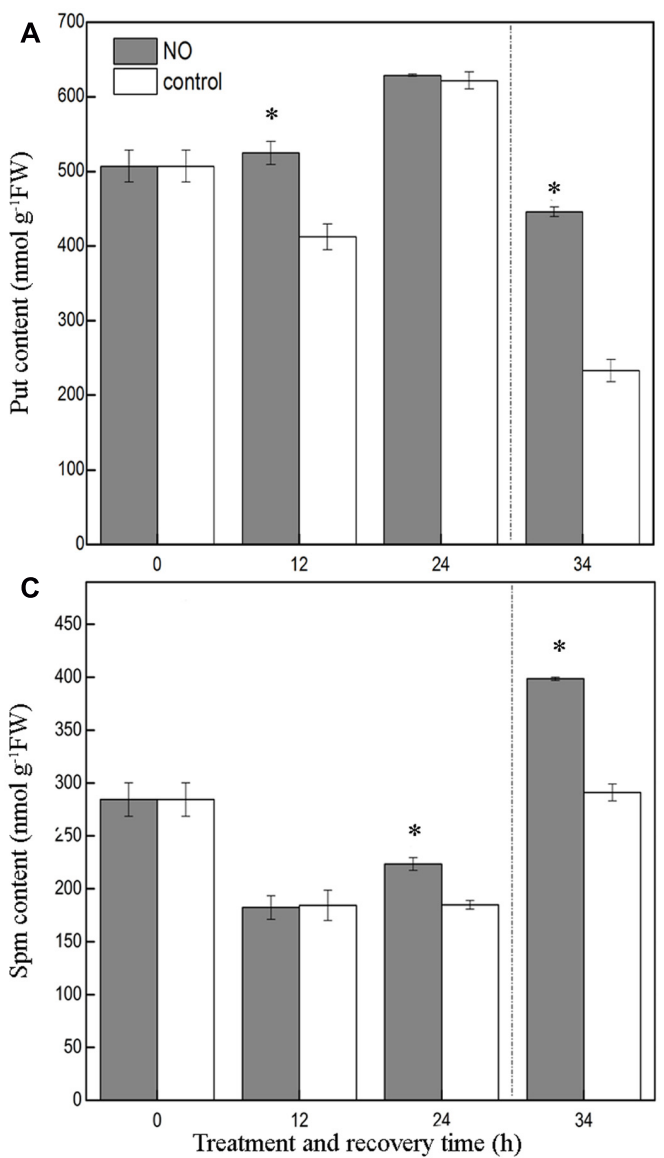

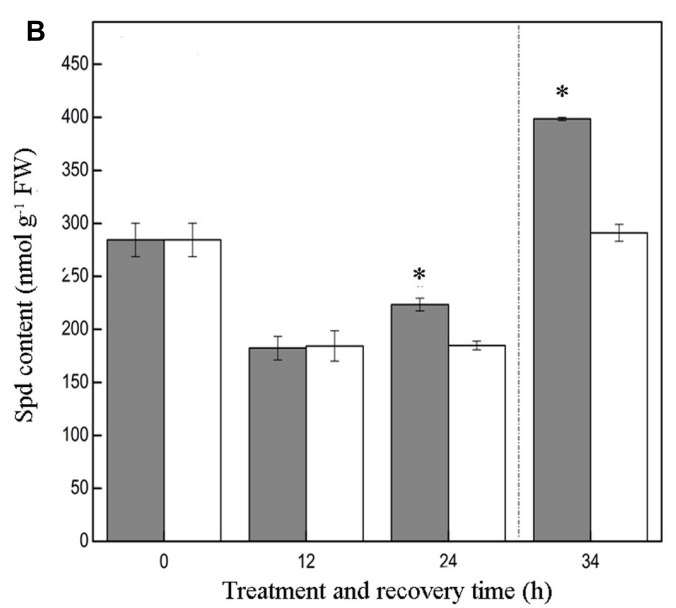

Treatment and recovery time $(\mathrm{h})$

FIGURE 5 | Effect of exogenous NO on PAs content in the leaves of tomato under chilling stress. (A) Put content, (B) Spd content, (C) Spm content. Tomato seedlings were treated with $200 \mu \mathrm{M} \mathrm{SNP}$ or distilled water (control), and exposed to chilling stress at $4^{\circ} \mathrm{C}(0,12$, and $24 \mathrm{~h})$, and recovery treatment $\left(25^{\circ} \mathrm{C}\right.$; $10 \mathrm{~h}$ ). Data represent the mean \pm SE of three independent experiments and asterisks represent significant differences compared to control at $P \leq 0.05$ according to Duncan's multiple range test.

(Figure 1A). We, therefore, suggest that exogenous Spd and Spm increased NO production under chilling stress. Analogously, Arasimowicz-Jelonek et al. (2009) suggested that Spd and Spm induced NO release in cucumber leaves under drought stress. Similar results were also observed in other studies (Groppa et al., 2008; Gong et al., 2014; Peng et al., 2015). However, Silveira et al. (2006) and Yang et al. (2014) suggested that exogenous Put greatly induced NO production in Araucaria angustifolia and in soybean. The contrasting results could be because the effect of PAs on NO production varied with the plant species, the type of PA, and the particular stress. NO production induced by PAs might be correlated with other physiological processes; for example, Santa-Catarina et al. (2007) observed that PAinduced NO plays a pivotal function in embryogenesis and Gong et al. (2014) reported that PA-induced NO production is beneficial in enhancing alkaline-stress tolerance. Similarly, in our previous studies, NO production was observed during Spd-induced chilling tolerance in tomato seedlings (Diao et al., 2016). Therefore, we speculate that in tomato seedlings either Spd or Spm may enhance chilling tolerance by inducing NO production.
Evidence obtained by Tun et al. (2006) showed that PAs induced NO production probably via an enzymatic pathway. Two potential sources of NO production, the NOS-like and NR enzymatic pathways, have been documented in plants (Desikan et al., 2002; Guo et al., 2003). In the present study, Spd and Spm induced NO generation through NR and NOS-like pathway in tomato seedlings under chilling stress (Figures 1B,C). Similar results were also obtained by Arasimowicz-Jelonek et al. (2009) in cucumber leaves during drought stress. There are several potential sources of NO generation in plants; however, the existence of any other enzymatic pathway that can directly lead to the PA-induced production of NO is unknown, and further studies are needed in this regard. In the present study, we assessed the transcript levels of LeNR and LeNOS1, which encode NR and NOS-like activity, respectively. The application of Spd and Spm increased the transcript levels of LeNR but reduced those of LeNOS1 under chilling stress (Figures 1D,E). The present results are in agreement with recent studies that indicate a principal role for NR in NO production (Gupta et al., 2011; Ziogas et al., 2015). However, these recent studies are inconsistent with regards to NO generation, most probably due to uncertainty concerning the 


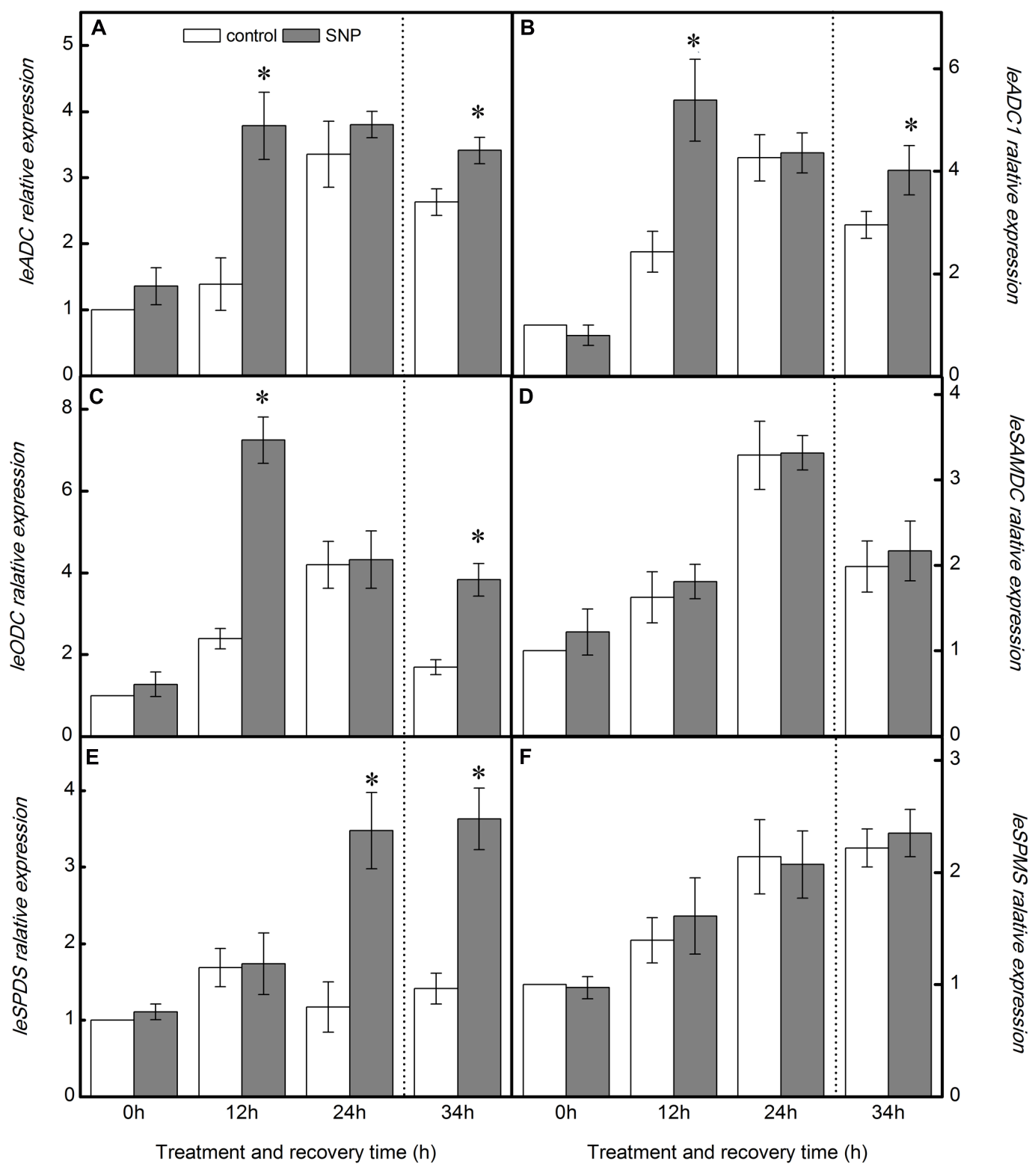

FIGURE 6 | Effect of exogenous NO on PAs biosynthetic enzyme genes relative expression in the leaves of tomato under chilling stress. (A) LeADC relative expression, (B) LeADC1 relative expression, (C) LeODC relative expression, (D) LeSAMDC relative expression, (E) LeSPDS relative expression, and (F) LeSPMS relative expression. The treatment details are as in the Figure 5. Data represent the mean \pm SE of three independent experiments and asterisks represent significant differences compared to control at $P \leq 0.05$ according to Duncan's multiple range test.

genes involved. There have been few studies involving the two genes, and in most cases, the involvement of the genes has been predicted rather than demonstrated directly. Further clarification is therefore required.

Polyamines-induced increase in $\mathrm{H}_{2} \mathrm{O}_{2}$ generation is closely linked to Put, Spd, or Spm catabolism (Wimalasekera et al., 2011a). It has been reported that low $\mathrm{H}_{2} \mathrm{O}_{2}$ levels serve as a signal in the signal transduction network of biotic and abiotic stresses (Tanou et al., 2009; Jiang et al., 2012), whereas high $\mathrm{H}_{2} \mathrm{O}_{2}$ levels can cause extensive cell injury or death (Quan et al., 2008). The present study showed that both Spd and Spm treatment, but not Put treatment, caused a large increase in the level of $\mathrm{H}_{2} \mathrm{O}_{2}$ compared to that in the control (Figure 2A). Furthermore, a significant increase in PAO activity was induced by the exogenous application of Spd or Spm, potential substrates for $\mathrm{H}_{2} \mathrm{O}_{2}$ generation (Figure 2C). Conversely, the application of Put had little effect on $\mathrm{H}_{2} \mathrm{O}_{2}$ content and induced no change in DAO activity. Similar results were obtained by Tanou et al. (2014) in citrus, and by Yoda et al. (2006), Moschou et al. (2008), and Iannone et al. (2013) in tobacco. Therefore, the present study strongly suggested that $\mathrm{H}_{2} \mathrm{O}_{2}$ production induced by Spd or Spm is related to increased $\mathrm{PAO}$ activity. 

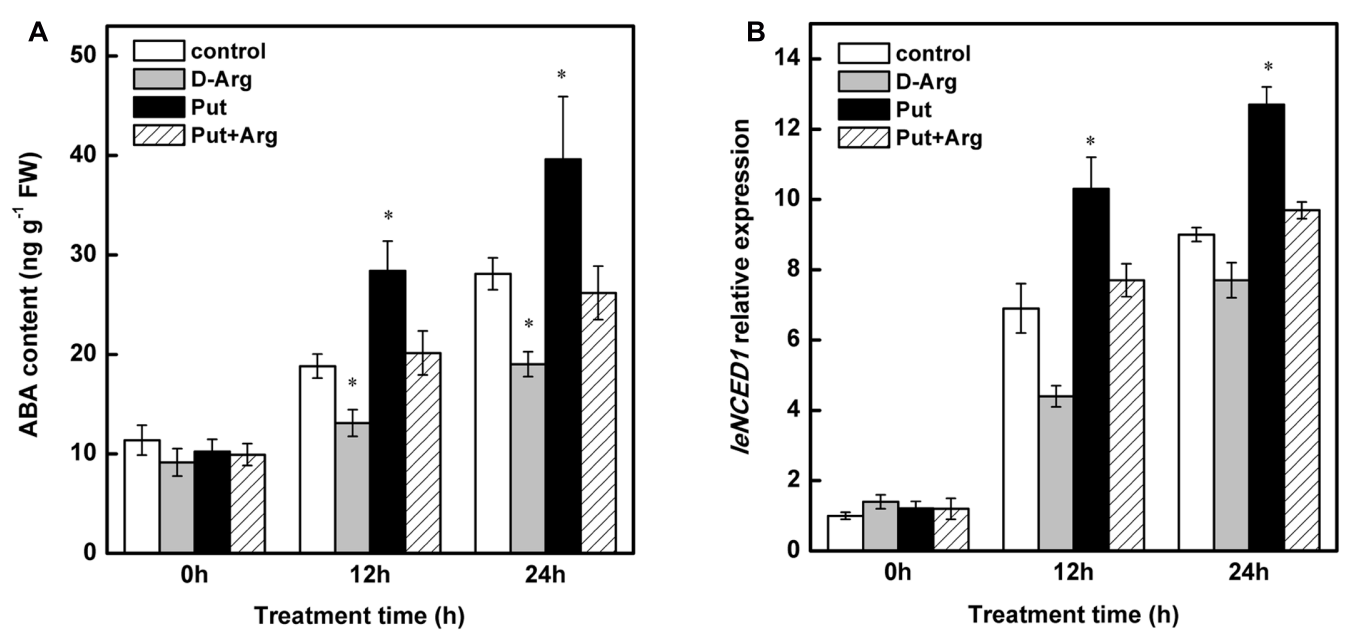

FIGURE 7 | Effect of exogenous Put and D-Arg on ABA content and NCED1 relative expression in the leaves of tomato under chilling stress. (A) ABA content, (B) NCED1 relative expression. Four treatments were used: (1) control; (2) 1 mM D-Arg; (3) 1 mM Put; (4) 1 mM D-Arg+ 1 mM Put. Seedlings were exposed to chilling stress at $4^{\circ} \mathrm{C}$ for $24 \mathrm{~h}$. Data represent the mean $\pm \mathrm{SE}$ of three independent experiments and asterisks represent significant differences compared to control at $P \leq 0.05$ according to Duncan's multiple range test.

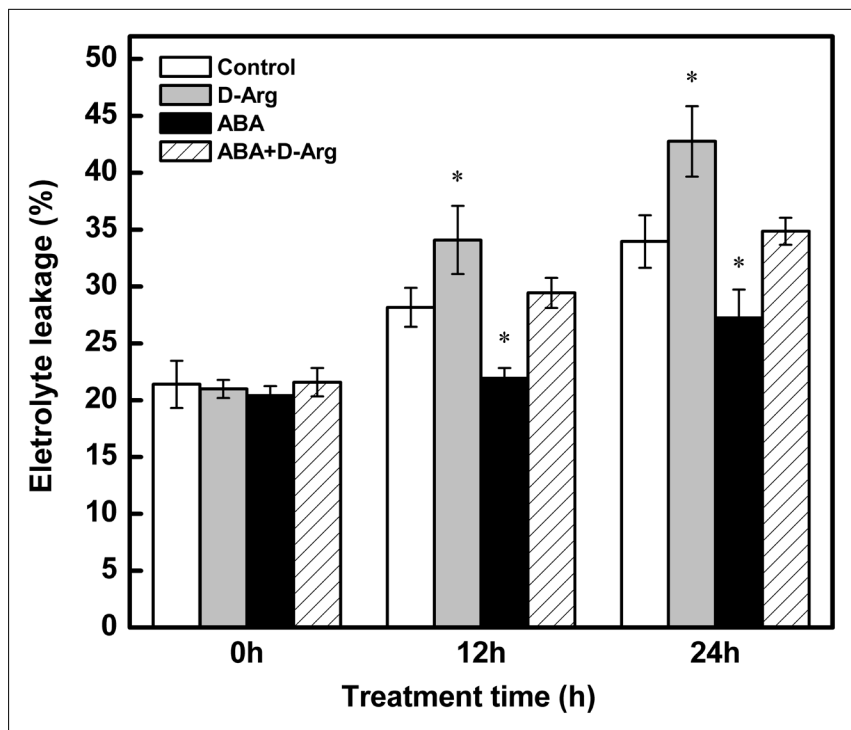

FIGURE 8 | Electrolyte Leakage of different treatments in tomato leaves during chilling stress. Four treatments were used: (1) control; (2) $1 \mathrm{mM}$ D-Arg; (3) $1 \mathrm{mM}$ ABA; (4) $1 \mathrm{mM}$ D-Arg + $1 \mathrm{mM}$ ABA. Seedlings were exposed to chilling stress at $4^{\circ} \mathrm{C}$ for $24 \mathrm{~h}$. Data represent the mean $\pm \mathrm{SE}$ of three independent experiments and asterisks represent significant differences compared to control at $P \leq 0.05$ according to Duncan's multiple range test.

Hydrogen peroxide and NO are signaling molecules; their generation often occurs in short bursts, one after the other or in parallel, and they can exert their influence synergistically or independently (Bright et al., 2006; Pasqualini et al., 2009). In our previous study, Spm showed little correlation with chilling resistance in tomato seedlings (Song et al., 2014a). Therefore, in the present study, we focused on the effect of Spd on the relationship between $\mathrm{H}_{2} \mathrm{O}_{2}$ and $\mathrm{NO}$ under chilling stress.

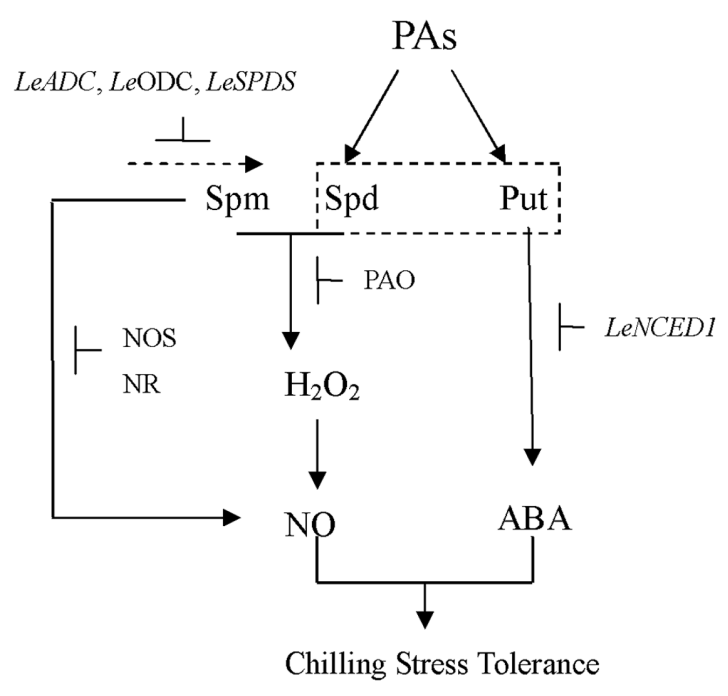

FIGURE 9 | The model of PAs signaling under chilling stress in tomato seedlings. Put induces the expression of LeNCED1, resulting in the increase of ABA level. Spd and Spm stimulate PAO activity; enhance NR and NOS-like activities, leading to the increase of $\mathrm{H}_{2} \mathrm{O}_{2}$ and $\mathrm{NO}$ generation. $\mathrm{H}_{2} \mathrm{O}_{2}$ may act as an upstream signal to stimulate NO production. In turn, SNP (an NO donor) improves Put and Spd contents through up-regulating the expression of LeADC, LeODC, and LeSPDS. NO and ABA are probably involved in PAs induced chilling stress tolerance.

We examined $\mathrm{H}_{2} \mathrm{O}_{2}$ and $\mathrm{NO}$ contents in plants treated with inhibitors and scavengers of $\mathrm{NO}$ and $\mathrm{H}_{2} \mathrm{O}_{2}$, prior to being treated with Spd. As shown in Figure 3, application of DPI and DMTU caused a decline in $\mathrm{H}_{2} \mathrm{O}_{2}$ content compared to plants treated with Spd alone (Supplementary Figure S1). Similarly, application of DPI and DMTU substantially repressed the Spd-induced increase in NO levels. In contrast, application of L-NAME, tungstate, and 
PTIO barely affected $\mathrm{H}_{2} \mathrm{O}_{2}$ levels when compared to the levels with Spd treatment alone (Figure 4). Thus, these results indicate that in tomato seedlings $\mathrm{H}_{2} \mathrm{O}_{2}$ may act upstream of $\mathrm{NO}$ to enhance its production under chilling stress. Similar effects were also found in Arabidopsis (Bright et al., 2006) and in maize leaves (Zhang et al., 2007). However, Pasqualini et al. (2009) indicated that $\mathrm{NO}$ treatment could increase $\mathrm{H}_{2} \mathrm{O}_{2}$ levels, whereas $\mathrm{NO}$ production showed little effect in response to $\mathrm{H}_{2} \mathrm{O}_{2}$ treatment in tobacco. Overall, it may be concluded that the interplay between $\mathrm{NO}$ and $\mathrm{H}_{2} \mathrm{O}_{2}$ in plants is complicated issue to elucidate, and that it depends upon the species, the types of stress, and the experimental conditions.

Several reviews have indicated that various abiotic stresses, including chilling stress, could induce different levels of PAs accumulation (Pang et al., 2007; Groppa and Benavides, 2008). We have also previously demonstrated that Put content increased in tomato seedlings under low-temperature conditions (Song et al., 2014a). To determine whether NO induces the generation of PAs, SNP was applied exogenously as a source of NO. In this experiment, pretreatment with NO led to increased Put levels at $12 \mathrm{~h}$ of chilling stress, and to increased Spd levels at $24 \mathrm{~h}$. The levels of both Put and Spd were also higher during the recovery period. In contrast, Spm levels were essentially unchanged throughout (Figure 5). As observed recently by Filippou et al. (2013), treatment with SNP led to enhancement of Put levels in Medicago truncatula plants plants. In addition, Fan et al. (2013) observed that exogenous SNP enhanced the salt tolerance of cucumber by increasing the $(\mathrm{Spd}+\mathrm{Spm}) / \mathrm{Put}$ ratio. Li et al. (2014) suggested that application of SNP could convert Put into Spd or Spm and confer tolerance to chilling stress. The results in the present study might be due to the direct induction of Put and Spd production by NO via an unknown pathway; however, it is possible that NO induced an increase in Put content alone, and that thereafter Put was converted into Spd.

In the work reported here, treatment with SNP greatly increased the expression of $L e O D C, L e A D C$, and LeADC1 at $12 \mathrm{~h}$ of chilling stress and during the recovery period (Figure 6), consistent with the observed Put accumulation (Figure 5). The increased LeSPDS expression could be responsible for the increase in the level of Spd at $24 \mathrm{~h}$ of chilling stress and during the recovery period. The application of SNP barely had an impact on the expression of LeSAMDC and LeSPMS (Figure 6), which appears consistent with the lack of change in Spm levels throughout the treatment period. The results revealed that exogenous NO might modulate the contents of PAs by influencing PA biosynthetic enzymes at the transcriptional level under chilling stress.

Furthermore, results from our previous research indicated that Put, unlike Spd, plays a crucial role in the tolerance of tomato to chilling stress (Song et al., 2014b). In the present study, application of Put had little effect on NO accumulation (Figure 1A); however, it could significantly increase endogenous ABA content and upregulate LeNCED1 under chilling stress (Figure 7). In addition, the increase in EL, induced by D-Arg, could be alleviated by ABA (Figure 8). These results suggest that $\mathrm{ABA}$ is essential for the Put-induced chilling-stress response. As suggested by Cuevas et al. (2008), Put could regulate ABA in response to low temperature.

Data from the present study have revealed the impact of exogenous PAs on $\mathrm{NO}$ and $\mathrm{H}_{2} \mathrm{O}_{2}$ (Figure 9). In addition, it appears that $\mathrm{H}_{2} \mathrm{O}_{2}$ might act upstream of $\mathrm{NO}$ in Spdtreated tomato leaves. These results clearly suggest that signaling involving PAs could correlate with other signaling intermediates. Based on the results of this and previous studies, we suggest that exogenous Spd could increase the chilling tolerance of tomato seedlings by inducing NO biosynthesis under chilling stress. Furthermore, the results of our previous study demonstrated that Put plays important roles in the chilling-stress tolerance of tomato seedlings. Hence, in the present study, the roles of Put and Spd in alleviating chilling stress were of particular interest. The results presented here suggest that Put may increase ABA content by inducing the expression of LeNCED1, thereby inducing chilling tolerance. we therefore suspect that cross-talk between $\mathrm{PAs}$ and $\mathrm{ABA}, \mathrm{NO}$, and $\mathrm{H}_{2} \mathrm{O}_{2}$ is involved in the response of tomato seedlings to chilling stress.

\section{CONCLUSION}

From the data obtained in this study, it is concluded that a link exists between PAs and NO during chilling stress in tomato seedlings. The exogenous application of Spd and Spm induced the generation of $\mathrm{NO}$ in an $\mathrm{H}_{2} \mathrm{O}_{2}$-dependent manner by NOSlike and NR pathways. Put could improve chilling tolerance via activation of ABA synthesis. Furthermore, under conditions of chilling stress, the application of $\mathrm{NO}$ enhanced endogenous Put and Spd levels through upregulation of the relevant PA biosynthetic genes.

\section{AUTHOR CONTRIBUTIONS}

QD and HQ designed research. QD and YS performed research. QD analyzed data. QD and HQ wrote the paper. YS and DS helped to revise the paper.

\section{FUNDING}

This work was supported by the China Agriculture Research System (Grant No.: CARS-25), and Liaoning Innovative Research Team in University (Grant No.: LZ2015025).

\section{SUPPLEMENTARY MATERIAL}

The Supplementary Material for this article can be found online at: http://journal.frontiersin.org/article/10.3389/fpls.2017.00203/ full\#supplementary-material

FIGURE S1 | Effect of DPI and DMTU on Spd-induced $\mathrm{H}_{2} \mathrm{O}_{2}$ production in the leaves of tomato under chilling stress $\left(4^{\circ} \mathbf{C}, 24 \mathbf{h}\right)$. (A) $\mathrm{H}_{2} \mathrm{O}_{2}$ content, (B) detection of $\mathrm{H}_{2} \mathrm{O}_{2}$ by DAB staining. Four treatments were used: (1) control; (2) 1 mM Spd; (3) 100 M DPI +1 mM Spd; (4) 5 mM DMTU+1 mM Spd. Data represent the mean \pm SE of three independent experiments and asterisks represent significant differences compared to control at $P \leq 0.05$ according to Duncan's multiple range test. 


\section{REFERENCES}

Alcázar, R., Altabella, T., Marco, F., Bortolotti, C., Reymond, M., Koncz, C., et al. (2010). Polyamines: molecules with regulatory functions in plant abiotic stress tolerance. Planta 231, 1237-1249. doi: 10.1007/s00425-010-1130-0

Anderson, M. D., Prasad, T. K., Martin, B. A., and Stewart, C. R. (1994). Differential gene expression in chilling-acclimated maize seedlings and evidence for the involvement of abscisic acid in chilling tolerance. Plant Physiol. 105, 331-339. doi: 10.1104/pp.105.1.331

Angelini, R., Tisi, A., Rea, G., Chen, M. M., Botta, M., Federico, R., et al. (2008). Involvement of polyamine oxidase in wound healing. Plant Physiol. 146, 162-177. doi: 10.1104/pp.107.108902

Arasimowicz-Jelonek, M., Floryszak-Wieczorek, J., and Kubiś, J. (2009). Interaction between polyamine and nitric oxide signaling in adaptive responses to drought in cucumber. J. Plant Growth Regul. 28, 177-186. doi: 10.1007/s00344-009-9086-7

Atıci, Ö., and Nalbantoǧlu, B. (2003). Antifreeze proteins in higher plants. Phytochemistry 64, 1187-1196. doi: 10.1016/S0031-9422(03)00420-5

Bais, H. P., and Ravishankar, G. A. (2002). Role of polyamines in the ontogeny of plants and their biotechnological applications. Plant Cell Tissue Organ Cult. 69, 1-34. doi: 10.1023/A:1015064227278

Besson-Bard, A., Pugin, A., and Wendehenne, D. (2008). New insights into nitric oxide signaling in plants. Annu. Rev. Plant Biol. 59, 21-39. doi: 10.1146/ annurev.arplant.59.032607.092830

Bright, J., Desikan, R., Hancock, J. T., Weir, I. S., and Neill, S. J. (2006). ABA induced NO generation and stomatal closure in Arabidopsis are dependent on H2O2 synthesis. Plant J. 45, 113-122. doi: 10.1111/j.1365-313X.2005.02615.x

Cona, A., Rea, G., Angelini, R., Federico, R., and Tavladoraki, P. (2006). Functions of amine oxidases in plant development and defence. Trends Plant Sci. 11, 80-88. doi: 10.1016/j.tplants.2005.12.009

Cuevas, J. C., Lopez-Cobollo, R., Alcázar, R., Zarza, X., Koncz, C., Altabella, T., et al. (2008). Putrescine is involved in Arabidopsis freezing tolerance and cold acclimation by regulating abscisic acid levels in response to low temperature. Plant Physiol. 148, 1094-1105. doi: 10.1104/pp.108.122945

de Pinto, M. C., Tommasi, F., De, and Gara, L. (2002). Changes in the antioxidant systems as part of the signaling pathway responsible for the programmed cell death activated by nitric oxide and reactive oxygen species in tobacco Bright-Yellow 2 cells. Plant Physiol. 130, 698-708. doi: 10.1104/pp.005629

Desikan, R., Griffiths, R., Hancock, J. T., and Neill, S. (2002). A new role for an old enzyme: nitrate reductase-mediated nitric oxide generation is required for abscisic acid-induced stomatal closure in Arabidopsis thaliana. Proc. Natl. Acad. Sci. U.S.A. 99, 16314-16318. doi: 10.1073/pnas.252461999

Diao, Q., Song, Y., and Qi, H. (2015). Exogenous spermidine enhances chilling tolerance of tomato (Solanum lycopersicum L.) seedlings via involvement in polyamines metabolism and physiological parameter levels. Acta Physiol. Plant. 37, 1-15. doi: 10.1007/s11738-015-1980-y

Diao, Q., Song, Y., Shi, D., and Qi, H. (2016). Nitric oxide induced by polyamines involves antioxidant systems against chilling stress in tomato (Lycopersicon esculentum Mill.) seedling. J. Zhejiang Univ. Sci. B 17, 916-930. doi: 10.1631/ jzus.B160010200425-010-1130-0

Dickinson, B. C., and Chang, C. J. (2011). Chemistry and biology of reactive oxygen species in signaling or stress responses. Nat. Chem. Biol. 7, 504-511. doi: $10.1038 /$ nchembio. 607

Dordas, C., Hasinoff, B. B., Igamberdiev, A. U., Manac'h, N., Rivoal, J., and Hill, R. D. (2003). Expression of a stress-induced hemoglobin affects NO levels produced by alfalfa root cultures under hypoxic stress. Plant J. 35, 763-770. doi: 10.1046/j.1365-313X.2003.01846.x

Duan, J. J., Li, J., Guo, S., and Kang, Y. (2008). Exogenous spermidine affects polyamine metabolism in salinity-stressed Cucumis sativus roots and enhances short-term salinity. J. Plant Physiol. 165, 1620-1635. doi: 10.1016/j.jplph.2007. 11.006

Durmus, N., and Kadioglu, A. (2005). Spermine and putrescine enhance oxidative stress tolerance in maize leaves. Acta Physiol. Plant. 27, 515-522. doi: 10.1007/ s11738-005-0057-8

Espasandin, F. D., Maiale, S. J., Calzadilla, P., Ruiz, O. A., and Sansberro, P. A. (2014). Transcriptional regulation of 9-cis-epoxycarotenoid dioxygenase (NCED) gene by putrescine accumulation positively modulates ABA synthesis and drought tolerance in Lotus tenuis plants. Plant Physiol. Biochem. 76, 29-35. doi: 10.1016/j.plaphy.2013.12.018

Fan, H. F., Du, C. X., and Guo, S. R. (2013). Nitric oxide enhances salt tolerance in cucumber seedlings by regulating free polyamine content. Environ. Exp. Bot. 86, 52-59. doi: 10.1016/j.envexpbot.2010.09.007

Filippou, P., Antoniou, C., and Fotopoulos, V. (2013). The nitric oxide donor sodium nitroprusside regulates polyamine and proline metabolism in leaves of Medicago truncatula plants. Free Radic. Biol. Med. 56, 172-183. doi: 10.1016/j. freeradbiomed.2012.09.037

Finkel, T., and Holbrook, J. N. (2000). Oxidants, oxidative stress and the biology of ageing. Nature 408, 239-247. doi: 10.1038/35041687

García-Mata, C., and Lamattina, L. (2001). Nitric oxide induces stomatal closure and enhances the adaptive plant responses against drought stress. Plant Physiol. 126, 1196-1204. doi: 10.1104/pp.126.3.1196

García-Mata, C., and Lamattina, L. (2002). Nitric oxide and abscisic acid cross talk in guard cells. Plant Physiol. 128, 790-792. doi: 10.1104/pp.011020

Gong, B., Li, X., Bloszies, S., Wen, D., Sun, S., Wei, M., et al. (2014). Sodic alkaline stress mitigation by interaction of nitric oxide and polyamines involves antioxidants and physiological strategies in Solanum lycopersicum. Free Radic. Biol. Med. 71, 36-48. doi: 10.1016/j.freeradbiomed.2014.02.018

Grant, J. J., and Loake, G. J. (2000). Role of reactive oxygen intermediates and cognate redox signaling in disease resistance. Plant Physiol. 124, 21-29. doi: 10.1104/pp.124.1.21

Groppa, M. D., and Benavides, M. P. (2008). Polyamines and abiotic stress: recent advance. Amino Acids 34, 35-45. doi: 10.1007/s00726-007-0501-8

Groppa, M. D., Rosales, E. P., Iannone, M. F., and Benavides, M. P. (2008). Nitric oxide, polyamines and Cd-induced phytotoxicity in wheat roots. Phytochemistry 69, 2609-2615. doi: 10.1016/j.phytochem.2008.07.016

Guo, F. Q., Mamoru, O., Nigel, M., and Crawford, N. M. (2003). Identification of a plant nitric oxide synthase gene involved in hormonal signaling. Science 302, 100-103. doi: 10.1126/science. 1086770

Gupta, K., Dey, A., and Gupta, B. (2013). Plant polyamines in abiotic stress responses. Acta Physiol Plant. 35, 2015-2036. doi: 10.1007/s11738-013-1239-4

Gupta, K. J., Fernie, A. R., Kaiser, W. M., and van Dongen, J. T. (2011). On the origins of nitric oxide. Trends Plant Sci. 16, 160-168. doi: 10.1016/j.tplants.2010. 11.007

Hatmi, S., Gruau, C., Trotel-Aziz, P., Villaume, S., Rabenoelina, F., Baillieul, F., et al. (2015). Drought stress tolerance in grapevine involves activation of polyamine oxidation contributing to improved immune response and low susceptibility to Botrytis cinerea. J. Exp. Bot. 66, 775-787. doi: 10.1093/jxb/ eru436

He, L. X., Nada, K., Kasukabe, Y., and Tachibana, S. (2002). Enhanced susceptibility of photosynthesis to low-temperature photoinhibition due to interruption of chill-induced increase of S-adenosylmethionine decarboxylase activity in leaves of spinach (Spinacia oleracea L.). Plant Cell Physiol. 43, 196-206. doi: 10.1093/ pcp/pcf021

Hu, X., Zhang, Y., Shi, Y., Zhang, Z., Zou, Z., Zhang, H., et al. (2012). Effect of exogenous spermidine on polyamine content and metabolism in tomato exposed to salinity-alkalinity mixed stress. Plant Physiol. Biochem. 57, 200-209. doi: 10.1016/j.plaphy.2012.05.015

Huang, X., Stettmaier, K., Michel, C., Hutzler, P., Mueller, M. J., and Durner, J. (2004). Nitric oxide is induced by wounding and influences jasmonic acid signaling in Arabidopsis thaliana. Planta 218, 938-946. doi: 10.1007/s00425003-1178- 1

Hung, K. T., Chang, C. J., and Kao, C. H. (2002). Paraquat toxicity is reduced by nitric oxide in rice leaves. J. Plant Physiol. 159, 159-166. doi: 10.1078/01761617-00692

Hussain, S. S., Ali, M., Ahmad, M., and Siddique, K. H. (2011). Polyamines: natural and engineered abiotic and biotic stress tolerance in plants. Biotechnol. Adv. 29, 300-311. doi: 10.1016/j.biotechadv.2011.01.003

Iannone, M. F., Rosales, E. P., and Groppa, M. D. (2013). H2O2 Involvement in polyamine-induced cell death in tobacco leaf discs. J. Plant Growth Regul. 32, 745-757. doi: 10.1007/s00344-013-9341-9

Iqbal, M., Ashraf, M., Jamil, A., and Rehman, S. (2006). Does seed priming induce changes in the levels of some endogenous plant hormones in hexaploid wheat plants under salt stress? J. Integr. Plant Biol. 48, 181-189. doi: 10.1111/j.17447909.2006.00181.x 
Jahromi, F., Aroca, R., Porcel, R., and Ruiz-Lozano, J. M. (2008). Influence of salinity on the in vitro development of Glomus intraradices and on the in vivo physiological and molecular responses of mycorrhizal lettuce plants. Microb. Ecol. 55, 45-53. doi: 10.1007/s00248-007-9249-7

Jiang, Y., Cheng, F., Zhou, Y., Xia, X. J., Mao, W. H., Shi, K., et al. (2012). Hydrogen peroxide functions as a secondary messenger for brassinosteroids-induced CO2 assimilation and carbohydrate metabolism in Cucumis sativus. J. Zhejiang Univ. Sci. B 13, 811-823. doi: 10.1631/jzus.B1200130

Kusano, T., Yamaguchi, K., Berberich, T., and Takahashi, Y. (2007). Advances in polyamine research. J. Plant Res. 120, 345-350. doi: 10.1007/s10265-0070074-3

Lamattina, L., Garcia-Mata, C., Graziano, M., and Pagnussat, G. (2003). Nitric oxide: the versatility of an extensive signal molecule. Annu. Rev. Plant Biol. 54, 109-136. doi: 10.1146/annurev.arplant.54.031902.134752

Laspina, N. V., Groppa, M. D., Tomaro, M. L., and Benavides, M. P. (2005). Nitric oxide protects sunflower leaves against Cd-induced oxidative stress. Plant Sci. 169, 323-330. doi: 10.1016/j.plantsci.2005.02.007

Li, X., Gong, B., and Xu, K. (2014). Interaction of nitric oxide and polyamines involves antioxidants and physiological strategies against chilling-induced oxidative damage in Zingiber officinale Roscoe. Sci. Hortic. 170, 237-248. doi: 10.1016/j.scienta.2014.03.026

Lopez-Carbonell, M., and Jauregui, O. (2005). A rapid method for analysis of abscisic acid (ABA) in crude extracts of water stressed Arabidopsis thaliana plants by liquid chromatography-mass spectrometry in tandem mode. Plant Physiol. Biochem. 43, 407-411. doi: 10.1016/j.plaphy.2005.02.006

Martin-Tanguy, J. (2001). Metabolism and function of polyamines in plants: recent development (new approaches). Plant Growth Regul. 34, 135-148. doi: 10.1023/ A:1013343106574

Minocha, R., Majumdar, R., and Minocha, S. C. (2014). Polyamines and abiotic stress in plants: a complex relationship. Front. Plant Sci. 5:175. doi: 10.3389/ fpls.2014.00175

Mittler, R. (2002). Oxidative stress, antioxidants and stress tolerance. Trends Plant Sci. 7, 405-410. doi: 10.1016/S1360-1385(02)02312-9

Moschou, P. N., Paschalidis, K. A., Delis, I. D., Andriopoulou, A. H., Lagiotis, G. D., Yakoumakis, D. I., et al. (2008). Spermidine exodus and oxidation in the apoplast induced by abiotic stress is responsible for $\mathrm{H} 2 \mathrm{O} 2$ signatures that direct tolerance responses in tobacco. Plant Cell 20, 1708-1724. doi: 10.1105/tpc.108. 059733

Murphy, M. E., and Noack, E. (1994). Nitric oxide assay using hemoglobin method. Methods Enzymol. 233, 240-250. doi: 10.1016/S0076-6879(94)3 3027-1

Neill, S., Barros, R., Bright, J., Desikan, R., Hancock, J., Harrison, J., et al. (2008). Nitric oxide, stomatal closure, and abiotic stress. J. Exp. Bot. 59, 165-176. doi: $10.1093 /$ jxb/erm293

Neill, S. J., Desikan, R., and Hancock, J. T. (2003). Nitric oxide signaling in plants. New Phytol. 159, 11-35. doi: 10.1046/j.1469-8137.2003.00804.x

Orozoco-Cardenas, M., and Ryan, C. A. (1999). Hydrogen peroxide is generated systemically in plant leaves by wounding and systemin via the octadecanoid pathway. Proc. Natl. Acad. Sci. U.S.A. 96, 6553-6557. doi: 10.1073/pnas.96.11. 6553

Pang, X. M., Zhang, Z. Y., Wen, X. P., Ban, Y., and Moriguchi, T. (2007). Polyamine, all-purpose players in response to environment stresses in plants. Plant Stress. 1, 173-188.

Pasqualini, S., Meier, S., Gehring, C., Madeo, L., Fornaciari, M., Romano, B., et al. (2009). Ozone and nitric oxide induce cGMP-dependent and-independent transcription of defence genes in tobacco. New. Phytol. 181, 860-870. doi: 10.1111/j.1469-8137.2008.02711.x

Patterson, B. D., Macrae, E. A., and Ferguson, I. B. (1984). Estimation of hydrogen peroxide in plant extracts using titanium (IV). Anal. Biochem. 139, 487-492. doi: 10.1016/0003-2697(84)90039-3

Peng, D., Wang, X., Li, Z., Zhang, Y., Peng, Y., Li, Y., et al. (2015). NO is involved in spermidine-induced drought tolerance in white clover via activation of antioxidant enzymes and genes. Protoplasma 253, 1243-1254. doi: 10.1007/ s00709-015-0880-8

Qin, X. Q., and Zeevaart, J. A. D. (1999). The 9-cis-epoxycarotenoid cleavage reaction is the key regulatory step of abscisic acid biosynthesis in water-stressed bean. Proc. Natl. Acad. Sci. U.S.A. 96, 15354-15361. doi: 10.1073/pnas.96.26. 15354
Quan, L. J., Zhang, B., Shi, W. W., and Li, H. Y. (2008). Hydrogen peroxide in plants: a versatile molecule of the reactive oxygen species network. J. Integr. Plant Biol. 50, 2-18. doi: 10.1111/j.1744-7909.2007.00599.x

Rockel, P., Strube, F., Rockel, A., Wildt, J., and Kaiser, W. M. (2002). Regulation of nitric oxide (NO) production by plant nitrate reductase in vivo and in vitro. J. Exp Bot. 53, 103-110. doi: 10.1093/jexbot/53.366.103

Saha, J., Brauer, E. K., Sengupta, A., Popescu, S. C., Gupta, K., and Gupta, B. (2015). Polyamines as redox homeostasis regulators during salt stress in plants. Front. Environ. Sci. 3:21. doi: 10.3389/fenvs.2015.00021

Sairam, R. K., and Srivastava, G. C. (2002). Changes in antioxidant activity in subcellular fraction of tolerant and susceptible wheat genotypes in response to long term salt stress. Plant Sci. 162, 897-904. doi: 10.1016/S0168-9452(02)00037-7

Santa-Catarina, C., Silveira, V., Scherer, G. F. E., and Floh, E. I. S. (2007). Polyamine and nitric oxide levels relate with morphogenetic evolution in somatic embryogenesis of Ocotea catharinensis. Plant Cell Tissue Organ Cult. 90, 93-101. doi: 10.1007/s11240-007-9259-7

Scheible, W. R., Gonzalez-Fontes, A., Lauerer, M., Muller-Rober, B., Caboche, M., and Stitt, M. (1997). Nitrate acts as a signal to induce organic acid metabolism and repress starch metabolism in tobacco. Plant Cell 9, 783-798. doi: 10.1105/ tpc.9.5.783

Schroeder, J. I., Kwak, J. M., and Allen, G. J. (2001). Guard cell abscisic acid signalling and engineering drought hardiness in plants. Nature 410, 327-330. doi: $10.1038 / 35066500$

Serna, M., Coll, Y., Zapata, P. J., Botella, M. Á., Pretel, M. T., and Amorós, A. A. (2015). A brassinos-teroid analogue prevented the effect of salt stress on ethylene synthesis and polyamines in lettuce plants. Sci. Hortic. 185, 105-112. doi: 10.1016/j.scienta.2015.01.005

Shen, W., Nada, K., and Tachibana, S. (2000). Involvement of polyamines in the chilling tolerance of cucumber cultivars. Plant Physiol. 124, 431-439. doi: 10. 1104/pp.124.1.431

Shi, S., Wang, G., Wang, Y., Zhang, L., and Zhang, L. (2005). Protective effect of nitric oxide against oxidative stress under ultrafiolet-B radiation. Nitric Oxide 13, 1-9. doi: 10.1016/j.niox.2005.04.006

Silveira, V., Santa-Catarina, C., Tun, N. N., Scherer, G. F., Handro, W., Guerra, M. P., et al. (2006). Polyamine effects on the endogenous polyamine contents, nitric oxide release, growth and differentiation of embryogenic suspension cultures of Araucaria angustifolia (Bert.) O. Ktze. Plant Sci. 171, 91-98. doi: 10.1016/j.plantsci.2006.02.015

Song, Y. J., Diao, Q. N., and Qi, H. Y. (2014a). Polyamine metabolism and biosynthetic genes expression in tomato (Lycopersicon esculentum Mill.) seedlings during cold acclimation. Plant Growth Regul. 75, 21-32. doi: 10.1007/ s10725-014-9928-6

Song, Y. J., Diao, Q. N., and Qi, H. Y. (2014b). Putrescine enhances chilling tolerance of tomato (Lycopersicon esculentum Mill.) through modulating antioxidant systems. Acta Physiol. 36, 3013-3027. doi: 10.1007/s11738-0141672-z

Tanou, G., Job, C., Rajjou, L., Arc, E., Belghzi, M., Diamantidis, G., et al. (2009). Proteomics reveal the overlapping roles of hydrogen peroxide and nitric oxide in the acclimation of citrus plants to salinity. Plant J. 60, 795-804. doi: 10.1111/ j.1365-313X.2009.04000.x

Tanou, G., Ziogas, V., Belghazi, M., Christou, A., Filippou, P., Job, D., et al. (2014). Polyamines reprogram oxidative and nitrosative status and the proteome of citrus plants exposed to salinity stress. Plant Cell Environ. 37, 864-885. doi: $10.1111 /$ pce. 12204

Tewari, R. K., Prommer, J., and Watanabe, M. (2013). Endogenous nitric oxide generation in protoplast chloroplasts. Plant Cell Rep. 32, 31-44. doi: 10.1007/ s00299-012-1338-5

Tun, N. N., Santa-Catarina, C., Begur, T., Silveira, V., Handro, W., Floh, E. I. S., et al. (2006). Polyamines induce rapid biosynthesis of nitric oxide (NO) in Arabidopsis thaliana seedlings. Plant Cell Physiol. 111, 721-724. doi: 10.1093/ pcp/pci252

Uchida, A., Jagendorf, A. T., Hibino, T., Takabe, T., and Takabe, T. (2002). Effects of hydrogen peroxide and nitric oxide on both salt and heat stress tolerance in rice. Plant Sci. 163, 515-523. doi: 10.1016/S0168-9452(02)00159-0

Verslues, P. E., Agarwal, M., Katiyar-Agarwal, S., Zhu, J., and Zhu, J. K. (2006). Methods and concepts in quantifying resistance to drought, salt and freezing, abiotic stresses that affect plant water status. Plant J. 45, 523-539. doi: 10.1111/ j.1365-313X.2005.02593.x 
Walters, D. (2003). Resistance to plant pathogens: possible roles for free polyamines and polyamine catabolism. New Phytol. 159, 109-115. doi: 10.1046/j.1469-8137. 2003.00802.x

Wang, G. J., Miao, W., Wang, J. Y., Ma, D. R., Li, J. Q., and Chen, W. F. (2013). Effects of exogenous abscisic acid on antioxidant system in weedy and cultivated rice with different chilling sensitivity under chilling stress. J. Agron. Crop Sci. 199, 200-208. doi: 10.1111/jac.12004

Wang, X., and Zhang, Y. (2012). Regulation of salicylic acid on polyamine synthesize under $\mathrm{NaCl}$ stress in leaves of the yali pear. Res. J. Appl. Sci. Eng. Technol. 4, 3704-3708.

Wimalasekera, R., Tebartz, F., and Scherer, G. F. (2011a). Polyamines, polyamine oxidases and nitric oxide in development, abiotic and biotic stresses. Plant Sci. 181, 593-603. doi: 10.1016/j.plantsci.2011.04.002

Wimalasekera, R., Villar, C., Begum, T., and Scherer, G. F. (2011b). Copper amine oxidase $1(\mathrm{CuAO} 1)$ of Arabidopsis thaliana contributes to abscisic acidand polyamine-induced nitric oxide biosynthesis and abscisic acid signal transduction. Mol. Plant 4, 663-678. doi: $10.1093 / \mathrm{mp} / \mathrm{ssr} 023$

Yamamoto, A., Shim, I. S., and Fujihara, S. (2012). Chilling-stress responses by rice seedlings grown with different ammonium concentrations and its relationship to leaf spermidine content. J. Plant Biol. 55, 191-197. doi: 10.1007/s12374-0110072-9

Yang, B., Wu, J., Gao, F., Wang, J., and Su, G. (2014). Polyamine-induced nitric oxide generation and its potential requirement for peroxide in suspension cells of soybean cotyledon node callus. Plant Physiol. Biochem. 79, 41-47. doi: 10. 1016/j.plaphy.2014.02.025

Yang, H., Wu, F., and Cheng, J. (2011). Reduced chilling injury in cucumber by nitric oxide and the antioxidant response. Food Chem. 127, 1237-1242. doi: 10.1016/j.foodchem.2011.02.011

Yoda, H., Hiroi, Y., and Sano, H. (2006). Polyamine oxidase is one of the key elements for oxidative burst to induce programmed cell death in tobacco cultured cells. Plant Physiol. 142, 193-206. doi: 10.1104/pp.106.080515

Zemojtel, T., Fröhlich, A., Palmieri, M. C., Kolanczyk, M., Mikula, I., Wyrwicz, L. S., et al. (2006). Plant nitric oxide synthase: a never-ending story? Trends Plant Sci. 11, 524-525. doi: 10.1016/j.tplants.2006.09.008
Zhang, A. Y., Jiang, M. Y., Zhang, J. H., Ding, H. D., Xu, S. C., Hu, X. L., et al. (2007). Nitric oxide induced by hydrogen peroxide mediates abscisic acidinduced activation of the mitogen activated protein kinase cascade involved in antioxidant defence in maize leaves. New Phytol. 175, 36-50. doi: 10.1111/ j.1469-8137.2007.02071.x

Zhang, Y., Wang, L., Liu, Y., Zhang, Q., Wei, Q., and Zhang, W. (2006). Nitric oxide enhances salt tolerance in maize seedlings through increasing activities of proton-pump and $\mathrm{Na}+/ \mathrm{H}+$ antiport in the tonoplast. Planta 224, 545-555. doi: 10.1007/s00425-006-0242-z

Zhao, L. Q., Zhang, F., Guo, J. K., Yang, Y. L., Li, B. B., and Zhang, L. X. (2004). Nitric oxide functions as a signal in salt resistance in the calluses from two ecotypes of reed. Plant Physiol. 134, 849-857. doi: 10.1104/pp.103.030023

Zheng, C., Jiang, D., Liu, F., Dai, T., Liu, W., Jing, Q., et al. (2009). Exogenous nitric oxide improves seed germination in wheat against mitochondrial oxidative damage induced by high salinity. Environ. Exp. Bot. 67, 222-227. doi: 10.1016/ j.envexpbot.2009.05.002

Zhou, B. Y., Guo, Z. F., Xing, J. P., and Huang, B. R. (2005). Nitric oxide is involved in abscisic acid-induced antioxidant activities in Stylosanthes guianensis. J. Exp Bot. 56, 3223-3228. doi: 10.1093/jxb/eri319

Ziogas, V., Tanou, G., Belghazi, M., Filippou, P., Fotopoulos, V., Grigorios, D., et al. (2015). Roles of sodium hydrosulfide and sodium nitroprusside as priming molecules during drought acclimation in citrus plants. Plant Mol. Biol. 89, 433-450. doi: 10.1007/s11103-015-0379-x

Conflict of Interest Statement: The authors declare that the research was conducted in the absence of any commercial or financial relationships that could be construed as a potential conflict of interest.

Copyright (c) 2017 Diao, Song, Shi and Qi. This is an open-access article distributed under the terms of the Creative Commons Attribution License (CC BY). The use, distribution or reproduction in other forums is permitted, provided the original author(s) or licensor are credited and that the original publication in this journal is cited, in accordance with accepted academic practice. No use, distribution or reproduction is permitted which does not comply with these terms. 